\title{
Nutrient density and bioaccessibility, and the antioxidant, satiety, glycemic, and alkalinizing potentials of fruit-based foods according to the degree of processing: a narrative review
}

Q2 a Université Clermont Auvergne, INRA, $Q$ Unité de Nutrition Humaine, CRNH Auvergne, Clermont-Ferrand, France; ${ }^{b}$ MOM Group, 2 e de la Pépinière, Paris, France

\begin{abstract}
Epidemiological studies suggest that the protective effects of fruits against chronic diseases may vary according to their extent of processing. We therefore reviewed what the scientific literature states about the potential mechanisms underlying this "processing" effect by focusing on the most significant nutritional properties, namely, the nutritional density of bioactive compounds, the digestive bio-accessibility of nutrients, and the antioxidant, satietogenic, alkalizing and glycemic potentials. When possible, we have ranked fruits according to the international NOVA classification as un-/minimally processed, processed (mainly with added sugars), and ultra-processed fruits. Our literature review confirms that the more fruits are processed, the lower are their alkalizing, antioxidant and satietogenic potentials. For the glycemic index, the results are more difficult to interpret because fruits are a significant source of fructose with a very low glycemic index that "distorts" the "processing" effect. However, fruits in sirup tend to have a higher glycemic index, probably because of the highly bioavailable added sugars. Overall, the destructuration of the fruit fibrous matrix by thermal and mechanical treatments, combined with the addition of simple sugars, constitute the treatments that most degrade the fruit nutritive quality by diluting the nutritional density and attenuating the "matrix" effect. The new technological processes described as "nonthermal" (e.g., pulsed electric fields, high pressures, supercritical $\mathrm{CO}_{2}$, radiation, etc.) seem promising as they limit vitamin $\mathrm{C}$ and antioxidant phytonutrient losses in fruit while allowing satisfactory storage time. To preserve fruit longer, drying appears to be an interesting alternative to maintain the health potential of fruit, although it causes antioxidant losses. Finally, although " 5 fruits and vegetables a day" is a well-known nutritional recommendation, in view of the results reviewed here, it would be relevant to be precise and include "preferably minimally processed".
\end{abstract}

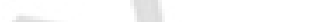

\section{Introduction}

Fruit products are highly varied, ranging from the least processed (fresh and dried fruits) to the most processed (fruit juice with added sugars, fruit-based sodas, ultraprocessed products containing fruit preparations such as filled or coated biscuits, dairy desserts, ice cream, etc.) with intermediate transformations (100\% fruit juice, canned fruit, compote, jams, etc.). However, the impact on the health of fruit products according to processing has never been systematically studied except sparsely in observational or interventional studies in humans (Fardet, Richonnet, and Mazur 2019).

In a first study, on the basis of 10 pooled analyses and meta-analyses, we have shown that there may exist a gradient of the protective effect of fruits according to the degree of processing, i.e., the least processed being the most protective (Fardet et al. 2019). This tendency might be in agreement with the international NOVA classification,

which ranks foods as un-/minimally processed, processed 92 and ultra-processed, with ultra-processed products being 93 the most deleterious for health (Monteiro et al. 2018). As 94 previously demonstrated on 98 (Fardet 2016), 280 (Fardet 95 et al. 2017) and 117 (Fardet, Lakhssassi, and Briffaz 2018) 96 ready-to-eat products, the explanations behind this first 97 global trend are probably at least three fold: 1) increased 98 accessibility of sugars as the transformation deconstructs the 99 matrix; 2) a low satiety potential due to a combined high 100 sugar content and unstructured fruit matrices, generating 101 further increased calorie intake; and 3) a deterioration of 102 nutritional density in protective micro- and phytonutrients 103 ("empty" calories). In addition, ultra-processed fruit drinks 104 are richer in free sugars through added sweeteners (e.g., 105 sucrose, glucose and fructose), which might favor nonalco- 106 holic fatty liver disease (Ouyang et al. 2008), insulin resist- 107 ance (Bremer, Auinger, and Byrd 2009; Hochuli et al. 2012; 108 McKeown et al. 2018), type 2 diabetes (Imamura et al. 2016; 109

CONTACT Anthony Fardet anthony.fardet@inra.fr 0 Université Clermont Auvergne, INRA, UNH, Unité de Nutrition Humaine, CRNH Auvergne, Clermont- 112 Ferrand F-63000, France.

Color versions of one or more of the figures in the article can be found online at www.tandfonline.com/bfsn. 
Wang et al. 2015), overweight and obesity (Ruanpeng et al. 2017). Moreover, although other studies are necessary to confirm the tendency, these results tend to show that we must favor whole fresh fruit and dried fruit, then $100 \%$ fruit juice without added sugars, and finally limit ultra-processed fruit products (Fardet et al. 2019). For canned/tinned fruit or fruits in sirup, jams and fruit purées or compotes, one cannot conclude because of a lack of studies, but it is likely that adding sugar (sucrose) or not plays an important role.

Following this first epidemiological approach to the relationship between fruit processing and the risk of chronic diseases (Fardet et al. 2019), the objective of this narrative review is to analyze in more details the influence of technological treatments on the health potential of fruit products according to the different processes, in particular with regard to the composition in bioactive micro- and phytonutrients; the glycemic, antioxidant, satiety and alkalinizing potentials; as well as the digestibility and bioaccessibility of nutrients of fruits, notably linked to the "matrix" effect (Fardet 2017; Fardet, Souchon, and Dupont 2013), to identify the least harmful processes for fruit products.

\section{What is food health potential? a new holistic definition more in line with reality}

Food health potential (FHP) cannot be defined based on only nutritional composition anymore (Fardet and Rock 2018). Two foods with different matrices and identical compositions (e.g., ground versus whole almonds) do not have the same health effects, notably with regard to the kinetics of nutrient release within the digestive tract, impacting further metabolic effects (Fardet 2015; Fardet et al. 2013). We eat food with matrices, not nutrients. Calories and nutrients are not interchangeable from one food to another, implying, for instance, that it is not the same impact on health to consume $100 \mathrm{kcal}$ from apple and $100 \mathrm{kcal}$ from flavored and sweetened soft drink, representing $100 \mathrm{kcal}$ of minimally processed or ultra-processed foods, respectively (Fardet and Rock 2018).

Based on recent research findings, the FHP has been redefined as a combination of both "matrix" and "composition" effects (Fardet and Rock 2018), i.e., FHP = "composition" x "matrix" effects, with "composition" being the quantitative and reductionist fraction and "matrix" the holistic and qualitative fraction resulting from specific nutrient interactions. This new holistic definition of FHP has fundamental consequences for human health, notably implying that a whole food is more protective than the sum of its reconstituted nutrients.

\section{A brief overview of the main fruit processes}

Processing not only impacts food composition but also the food matrix, notably through unstructuration, refining and cracking. The modification of the fruit matrix is important because it may potentially play a role in the bioavailability of sugars, feeling of satiety and speed of digestive transit (Fardet and Rock 2018). It is therefore not harmless to health to unstructure the fruit matrix. Technologists are used to distinguishing between processes that preserve (Brat and Cuq 2007b) and those that alter (Brat and Cuq 2007a) the initial structure of fruits.

\section{Processes that preserve the fruit matrix}

In 2007, Brat and Cuq proposed a schematic representation of the different technological pathways that can be used for fruit processing while preserving the original structure (Figure 1) (Brat and Cuq 2007b). In view of the applied treatments, namely, washing, sorting, sizing, trimming (pitting, tailing and peeling), cutting, blanching (1-2 minutes in boiling water), preserving, drying and packaging, these fruit products may be predominantly considered to be minimally processed according to the NOVA classification (Monteiro et al. 2016).

Fruit conservation techniques that preserve the original structure can be grouped into five categories, as described by Brat and Cuq (2007b):

- Ready-to-use fruits, comprising products that have undergone minimal processing (direct consumption) and for which the storage conditions guarantee the quality of end-of-life products.

- Frozen fruits (without added sugars), comprising products that are preserved by the implementation of negative temperatures sufficient to block the degradation reactions; however, freezing, under the mechanical effect of the large ice crystals present in the interstices, destroys the cellular integrity of fruits because the initial rigidity of the outer cellulosic wall depends on the state of the pectic cement linked to the maturity of the fruits. Upon thawing, Brat and Cuq explained that "the water contained in the cellular interstices causes an exudate, all the richer in soluble constituents that the process will be slow... The exudate carries with it both water-soluble vitamins, sugars and minerals. It should therefore be consumed to limit nutritional losses" (page 12) (Brat and Cuq 2007b).

- Canned fruit, comprising products for which heat treatment has been implemented to inactivate the factors causing fruit degradation reactions (microbiological, physiological and enzymatic) and which are conditioned in packaging to prevent recontamination during storage.

- Dried fruits through thermal treatments, comprising products that have been partially dehydrated (and therefore not absolutely dry) to be stored for a long time, fabricated from fruit whose dry matter does not exceed 30\% of the wet weight; this helps to lower the water activity in the fruit matrix, causing modification of the initial structure.

- Dried fruits through the dewatering-impregnation soaking process (DISP), which consists of putting in contact with the fruit, whole or fractionated, a solution that is highly concentrated in sugars, i.e., (semi)candied fruits. In general, an outlet of water from the product to the 


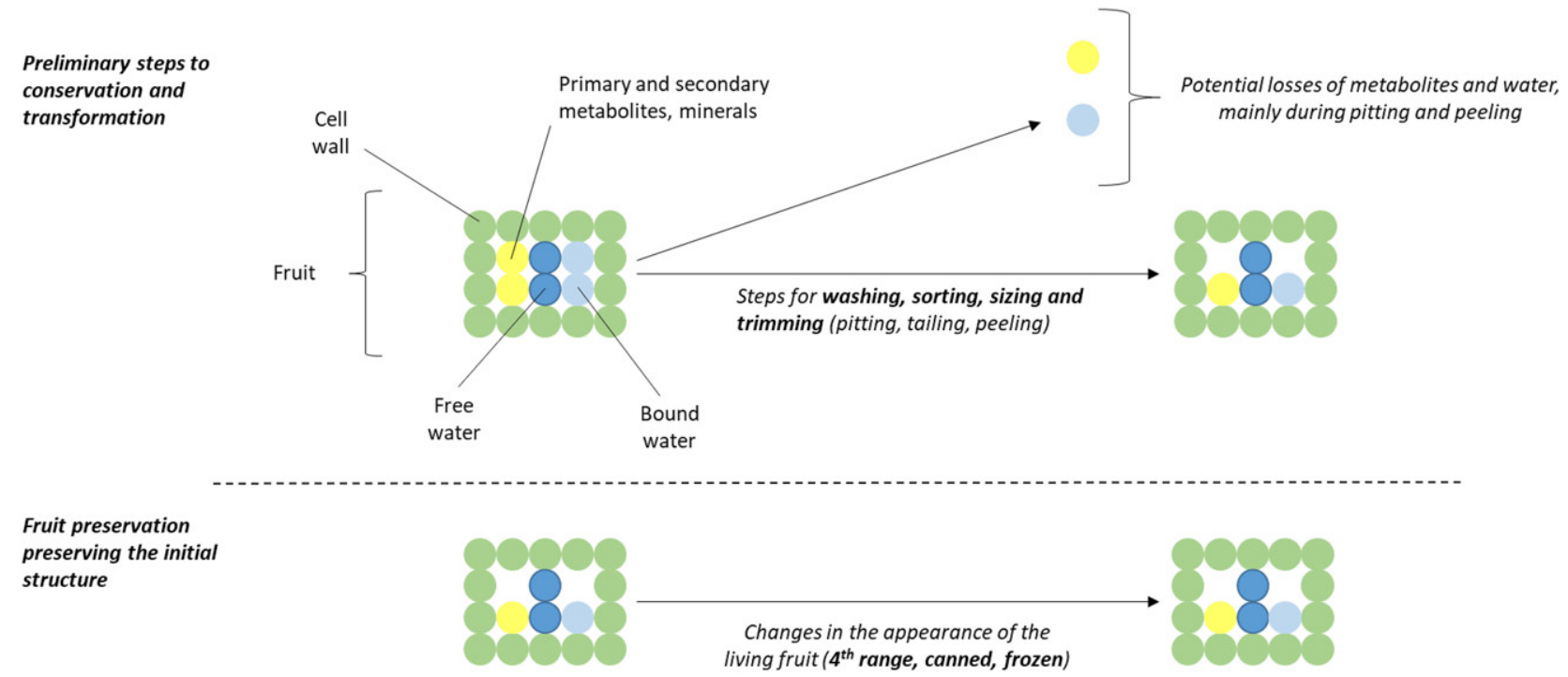

Figure 1. Schematic representation of the different technological paths that can be used to process agricultural raw materials while preserving the initial structure 316 (reproduced from Brat and Cuq (2007b) with permission of Editions des Techniques de L'Ingénieur ${ }^{\circ}$ ).

solution and a transfer of sugar to the product in the opposite direction occur.

None of these treatments is neutral towards the initial FHP and integrity. In addition to thermal treatments, one must also mention ionizing radiation (a nonthermal process such as ionization with $\gamma$-rays, X-rays or accelerated electron beams) that allows for the destruction of microorganisms and insects and inhibition of physiological processes of germination.

\section{Processes that alter the fruit matrix}

There are three main groups of processes that alter the fruit matrix (Figure 2) (Brat and Cuq 2007a):

- Fruit preservation after extraction, separation and/or processing, which includes juices, purees, concentrates and jams.

- Fruit fermentation, which includes products such as wine and alcohols of various fruits and varieties (distilled alcohols, liquors and brandies).

- Cracking of functional elements of fruits, e.g., pectins, sugars.

Fruits can be directly pressed to obtain a juice provided that the proportion of free water is high enough (Brat and Cuq 2007a). Once the juice is obtained, it is subjected, depending on the type of fruit, to different stages of enzymatic treatments before being concentrated or pasteurized as such. The average water content of the juices is approximately $88 \%$. One distinguishes two types of fruit juices:
$100 \%$ pure fruit juices obtained by simple pressing of fruits, 319 without the addition of any sugar and/or additives, and fruit 320 juices from concentrates, mainly from citrus fruits. The 321 products are reconstituted by reincorporating concentrated 322 fruit juice with the same quantity of water as that extracted 323 during the concentration. This concentration is intended to 324 facilitate storage and transportation. Otherwise, although not 325 widespread, fruit juices may be preserved and stabilized with 326 very high-pressure treatments (up to 4000 bars) instead of 327 thermal treatments, which notably allows better preservation 328 of nutritional properties.

As written by Brat and Cuq: "When the free water content 330 is naturally low in a fruit (e.g., apricot, mango, peach, ...) 331 and the content in cell walls is high, a simple pressing of the 332 fruit does not allow, under any circumstances, a good recov- 333 ery of the fruit extraction product, even after a possible lique- 334 fying treatment. A fruit puree is therefore defined as a 335 fermentable, but unfermented, product obtained by sieving 336 the edible portion of whole or peeled fruits without removing 337 the juice" (page 6) (Brat and Cuq 2007a).

From the raw purees obtained, a liquefying enzymatic 339 treatment may be useful for future preparation of nectars 340 (Brat and Cuq 2007a). As defined by the Official Journal of 341 the European Communities (Directive 2001/112 du 20/12/ 343 2001), a nectar is a fermentable product, but not fermented, 344 obtained by adding water and sugars (mainly sucrose) and/ 345 or honey to fruit puree (Légifrance 2001). Jam and its 346 related products, such as jelly or marmalade, are the result 347 of the gelling of fruit pectins and sugar during cooking 348 (Brat and Cuq 2007a). Gelling occurs when the mixture 349 cools to room temperature. Fermentation is the process in 350 
Fruit preservation after extraction, separation and/or fractionation

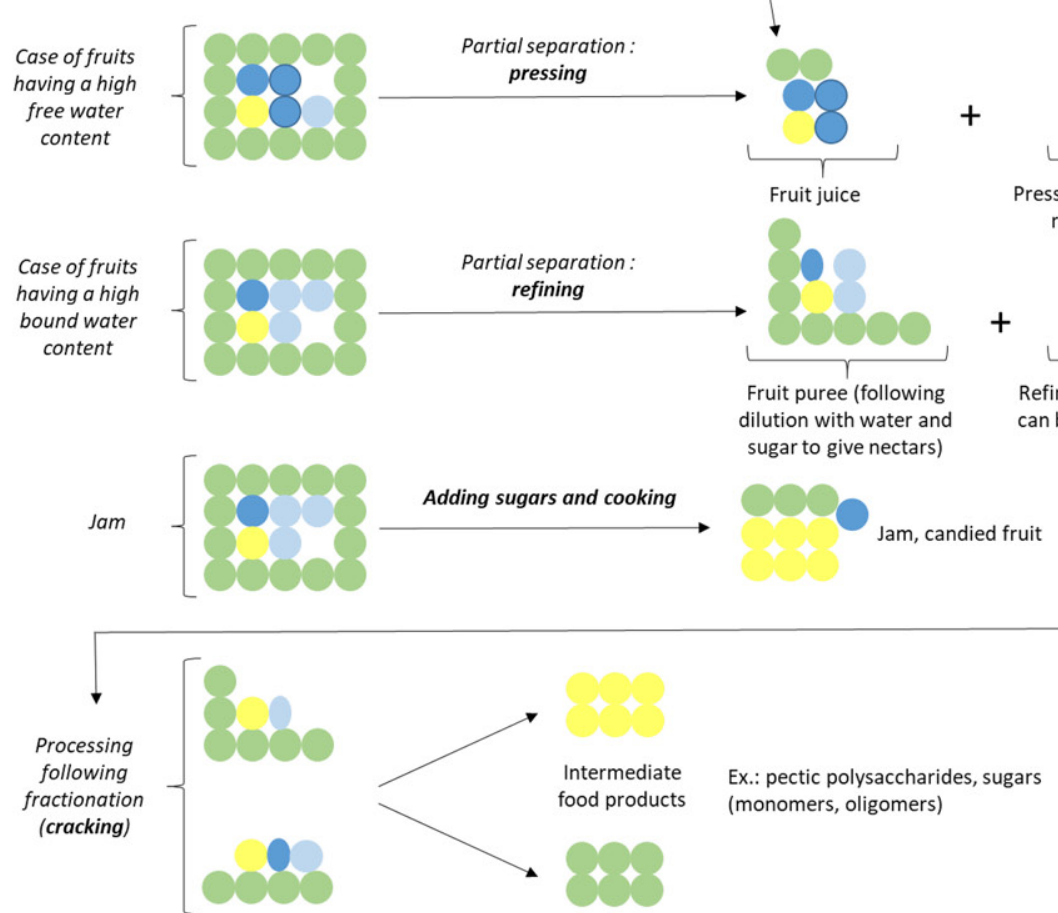

Figure 2. Various technological methods of fruit conservation (reproduced from Brat and Cuq (2007a) with permission of Editions des Techniques de L'Ingénieur ${ }^{\complement}$ ).

which sugar is converted to alcohol by yeast. Adding sugar to fruit bases will increase the alcohol levels achieved during fermentation. Once a fruit base or mash has been fermented, it can be strained to produce fruit wine or distilled to make fruit liquor.

Finally, when processing fruits as juices, purees, nectars or jams, one obtains co- or byproducts (Brat and Cuq 2007a). While coproducts are rejected fruits during the step of selection, byproducts represent products obtained during the different steps of processing (e.g., skins, seeds, essential oils, in the case of citrus fruits) (Brat and Cuq 2007a). One distinguishes agropolymers such as polysaccharides and pectins, and micronutrients such as aromas and colorants (e.g., carotenoid extraction with the use of supercritical $\mathrm{CO}_{2}$ ).

\section{Influence of processing on the fruit nutrient density}

The influence of processing on fruit nutrient density may be studied through either nutrient databases or published peerreviewed articles.

\section{From the American USDA database}

The most complete nutrient database for fruit-based products is the USDA (U.S. Department of Agriculture 2005). The orange and the apple, because of their frequent consumption worldwide, especially in Western countries, have been chosen as examples. The contents are expressed per $100 \mathrm{~g}$ of dry matter so that the comparisons are made on the same basis, with fruit-based products not having the same water content in the tables according to the process applied.
Eight orange products were compared to the whole fruit (left column) for nutrient levels (Table 1). It is interesting to focus on the protective nutrients characteristic of fruits such as fiber, minerals and vitamins. The fiber content decreases sharply after pressing the orange into $100 \%$ fresh juice, chilled juice from concentrate, canned juice, frozen concentrated juice, nectar and marmalade (divided by approximately a factor of 10). It is close to 0 in soda and Tang. The content of total minerals and total vitamins (especially vitamin C) decreases, especially for nectar, sodas, Tang $(\mathbb{C}$ and marmalade, while juices and fruits have fairly equivalent levels.

For apple, nine products were compared to the whole fruit (left column) for nutrient content: boiled apples, compote, juice, concentrated frozen juice, canned, dried and frozenheated apples (Table 2). As with orange, pressing strongly reduces the fiber content, while canned compote or slices keep a fiber content close to the whole apple, even if slightly lower. The total mineral content decreases after processing except for the juices. Draining apples after canning probably explains the significant loss of minerals in these products (divided by approximately two). The total vitamin content decreases much more strongly in all products compared to the whole apple, especially for drained canned apples. Undrained canned apple compote has a total vitamin content approximately six times higher than drained canned slice apples. Among vitamins, vitamin $\mathrm{C}$ is particularly affected.

\section{From the French Ciqual database}

Another source of data is the nutritional compositions of the foods listed in the French Ciqual database of ANSES (ANSES-Afssa 2008). One hundred thirty-eight products 

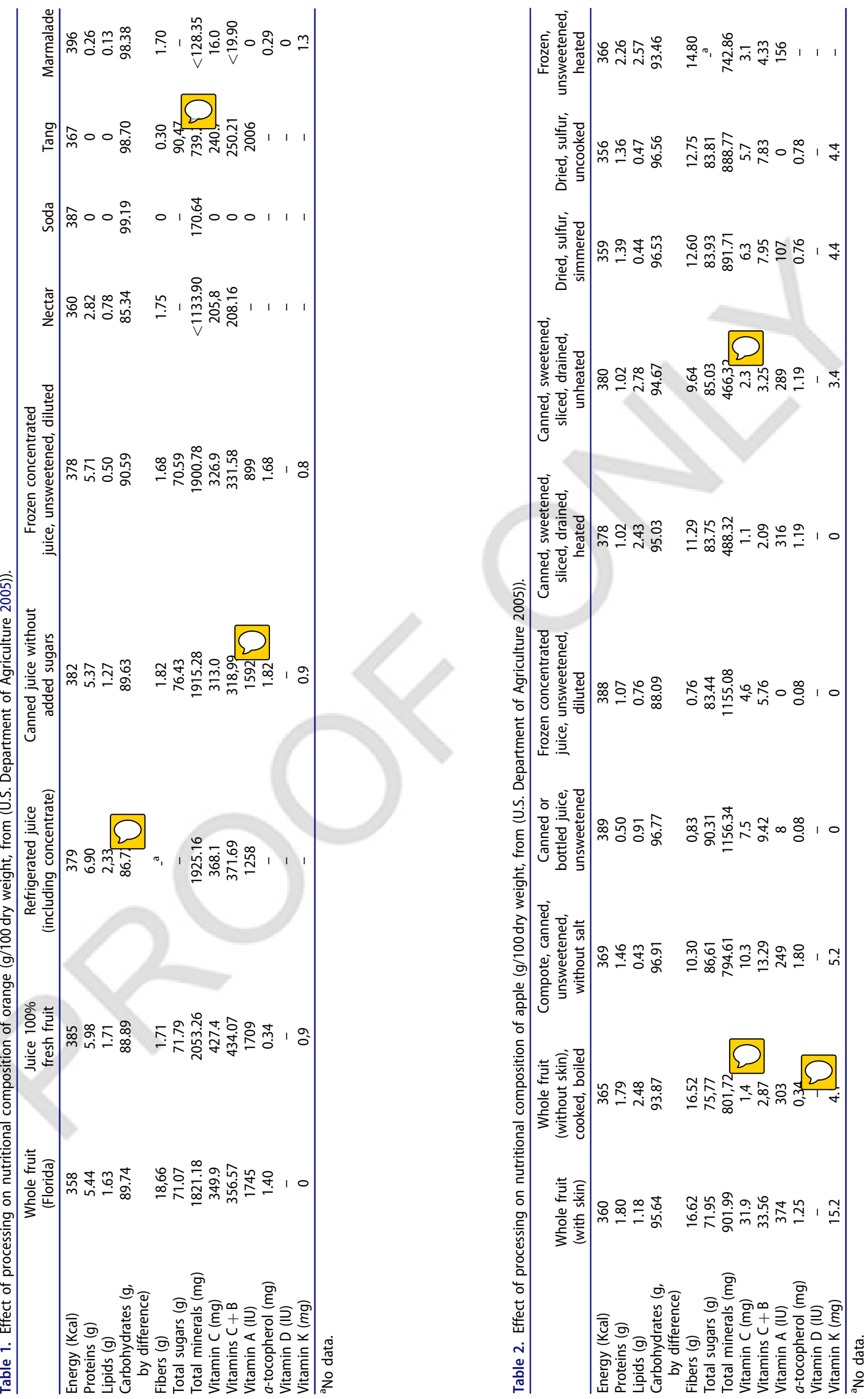
Table 3. NDS and LIM indices of fruit-based foods $(n=138)$ according to degree of food processing (based on NOVA classification, fruit-based alcool excluded).

\begin{tabular}{lll}
\hline Technological groups & NDS & LIM \\
\hline${\text { Un-/minimally processed }(\mathrm{n}=68)^{\mathrm{a}}}^{\mathrm{a}}$ & 7.25 & 0.12 \\
${\text { Processed }(\mathrm{n}=28)^{\mathrm{a}}}_{\text {Complex fruit-based desserts }^{\mathrm{c}}(\mathrm{n}=28)^{\mathrm{a}}}$ & 3.49 & $-{ }^{\mathrm{b}}$ \\
\hline
\end{tabular}

${ }^{a}$ Number of fruit items: fruit-based food composition obtained from French Ciqual database (ANSES-Afssa 2008).

${ }^{\mathrm{b}}$ No data on added sugar.

'Included processed (NOVA group 3) and ultra-processed (NOVA group 4) foods.

were selected as fruit products or containing a portion of fruit. The products were classified into three NOVA technological groups as previously described (Moubarac et al. 2014): un-/minimally processed (61 foods); processed (41 foods); and ultra-processed (36 foods). From their composition, the NDS (Nutrient Density Score) of these foods (Darmon et al. 2009) was calculated, and the median is given for each NOVA group (Table 3). Fruit-based products have been ranked as un-/minimally processed (raw, dried, pressed and/or cooked fruits without added sugars), processed (fruits with added sugars: canned fruits with sirup, nectars, fruit cocktail, jams and marmalades, fruit juices with added sugars), and fruit-based desserts. Due to the lack of information about ingredients/additives used in the Ciqual database for fruit-based desserts, this group may include both processed and ultra-processed foods. In addition, no data are available on added sugars, which explains why the LIM (nutrient to limit) index could not have been calculated for processed and complex fruit-based desserts.

The NDS decreases from un-/minimally processed fruits (median $=7.25)$ to processed fruits (3.49) and complex fruitbased desserts (3.33), mainly because of fiber and micronutrient (i.e., vitamins $\mathrm{C}, \mathrm{E}, \mathrm{B} 1, \mathrm{~B} 2, \mathrm{~B} 6$, and $\mathrm{B} 9$ and calcium, iron, magnesium, zinc, and potassium) losses. As expected, the LIM index is very low in the NOVA group 1 of un- $/$ minimally processed fruits $(0.12)$. Fruit-based products in the processed NOVA group 3 are characterized by the addition of sugars; therefore, there is no doubt that this would have greatly increased the median LIM index to higher than that of fresh/dried fruits. If we go into detail for fruit products in NOVA group 1, we observe that fresh fruits, fruit purées and $100 \%$ fruit juices are the fruit products with the best nutritional densities (results not shown). However, from the whole fruit to the juice, the "matrix" effect is altered.

\section{From original articles}

It is difficult to study the degradation of fibers, micronutrients and phytonutrients of fruits according to the different types of technological treatments applied because a fruit product is often the result of the application of several treatments, both mechanical, thermal, and/or fermentative. Additionally, after a careful examination of the literature, it seems more relevant to present the data of the literature by type of compound:
Table 4. Average fiber content of fresh apple and applesauce ( $n=8$ samples) (reproduced from Colin-Henrion et al. (2009) with permission of Elsevier (C).

\begin{tabular}{lcc}
\hline Fiber content $(\mathrm{g} / 100 \mathrm{~g}$ fresh weight) & Fresh whole apple & Applesauce \\
\hline Fraction insoluble in alcohol & $2.43(16.20)^{\mathrm{a}}$ & $1.76(6.52)$ \\
Total fiber & $2.33(15.53)$ & $1.68(6.22)$ \\
Insoluble fiber & $1.69(11.27)$ & $1.02(3.78)$ \\
Soluble fiber & $0.64(4.27)$ & $0.66(2.44)$ \\
Soluble/lnsoluble fiber & 0.38 & 0.65 \\
\hline
\end{tabular}

${ }^{a}$ Content $(\mathrm{g})$ by $100 \mathrm{~g}$ dry weight: apple $\approx 85 \%$ water; compote $\approx 73 \%$ water.

\section{The fiber fraction}

The production of applesauce with added sugars is interesting because it involves several stages of processing. ColinHenrion et al. included sorting (damaged products are removed), cooking, refining through a $1.2-\mathrm{mm}$ filter, the addition of glucose-fructose sirup and pasteurization (ColinHenrion et al. 2009). The total fiber content $(\mathrm{g} / 100 \mathrm{~g}$ of fresh matter) decreased by $28 \%$ between the whole apple and the corresponding compote, notably due to the addition of sugars and the removal of the skin (refining), which is rich in insoluble fibers. As a consequence, the main decrease concerns the insoluble fiber $(-40 \%)$, but the soluble fiber content is rather stable $(+3 \%)$ (Table 4$)$. As a result, the soluble/insoluble fiber ratio is almost doubled (from 0.38 to 0.65 ).

If we look at the different stages of processing, the total fiber content shifted from 13.9 to $11.6 \mathrm{~g} / 100 \mathrm{~g}$ of dry matter between sorting and pasteurization, and the percentage of insoluble fibers decreased by $12 \%$ (Table 5). The largest decrease in insoluble fiber occurred at the time of refining $(-10 \%)$. The effect is much less marked after approximately two months of storage in a controlled atmosphere (Batch B: see note at the bottom of Table 5). For Batch A, the increase in total fiber content after cooking is due to both soluble and insoluble fiber. For the authors, two possible explanations are "the loss of some internal soluble materials (by dripping of the sugar solution) or a sampling bias, namely, a change in the skin/pulp/seed ratio between fresh apples and cooked apple broth" (Colin-Henrion et al. 2009). According to the authors, during the processing of apples into applesauce, two main mechanisms can affect the fiber content: 1) heating, which leads to a depolymerization of the pectins; and 2) mechanical separation of the most resistant fractions, namely, pips, skin and carpels (Colin-Henrion et al. 2009). The soluble fiber content increases after cooking: the applied temperature $\left(85^{\circ} \mathrm{C}\right)$ may have contributed to the solubilization by depolymerization of the cell wall polysaccharides previously bound to the insoluble fraction, most probably the pectins. Finally, the authors mentioned the potential formation of insoluble complexes induced by the process, likely to increase the content of insoluble fibers, i.e., Maillard reaction products during cooking, and the interaction of polyphenols with cell wall polysaccharides. Thus, "the pulp/peel/seed ratio and the insoluble aggregates may have contributed to an increase in the levels of polysaccharides and insoluble fibers during cooking, more or less offsetting the loss of insoluble polysaccharide by pectic solubilization" (Colin-Henrion et al. 2009). In conclusion, the processing of apples into applesauce represents only 


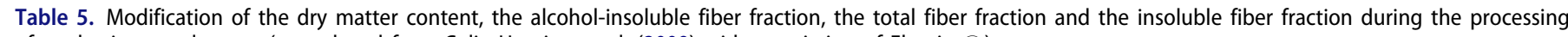
of apples into applesauce (reproduced from Colin-Henrion et al. (2009) with permission of Elsevier(C)).

\begin{tabular}{|c|c|c|c|c|c|}
\hline \multirow[b]{2}{*}{ Batch } & \multirow[b]{2}{*}{ Transformation stage } & \multirow[b]{2}{*}{$\begin{array}{l}\text { Dry matter content } \\
\text { (g/100 g fresh weight) }\end{array}$} & \multicolumn{3}{|c|}{ Fiber content ( $\mathrm{g} / 100 \mathrm{~g}$ dry weight corrected by added sugar) } \\
\hline & & & $\begin{array}{l}\text { Alcohol-insoluble } \\
\text { fraction }\end{array}$ & Total fiber & $\begin{array}{l}(\%) \text { insoluble } \\
\text { fiber }(\mathrm{g} / 100 \mathrm{~g})\end{array}$ \\
\hline \multirow[t]{5}{*}{ Batch $A^{a}$} & Sorting & 16.4 & 14.9 & 13.9 & 72 \\
\hline & Cooking $\left(15 \mathrm{~min}\right.$ at $\left.85^{\circ} \mathrm{C}\right)$ & 16.0 & 19.1 & 17.4 & 70 \\
\hline & Refining (1.2 mm mesh size) & 14.7 & 15.5 & 14.0 & 60 \\
\hline & $\begin{array}{l}\text { Sugaring ( } 15 \% \text { of fructose-glucose } \\
\text { sirup, } 85^{\circ} \text { Brix) }\end{array}$ & 16.5 & 12.6 & 12.6 & 57 \\
\hline & Pasteurization $\left(2-3 \min\right.$ at $\left.90^{\circ} \mathrm{C}\right)$ & 16.5 & 12.5 & 11.6 & 60 \\
\hline \multirow[t]{5}{*}{ Batch B } & Sorting & 15.0 & 16.1 & 16.0 & 73 \\
\hline & Cooking $\left(15 \mathrm{~min}\right.$ at $\left.85^{\circ} \mathrm{C}\right)$ & 13.9 & 18.2 & 16.7 & 67 \\
\hline & Refining (1.2 mm mesh size) & 14.3 & 15.9 & 13.2 & 66 \\
\hline & $\begin{array}{l}\text { Sugaring ( } 15 \% \text { of fructose-glucose } \\
\text { sirup, } 85^{\circ} \text { Brix) }\end{array}$ & 15.5 & 13.1 & 13.1 & 52 \\
\hline & Pasteurization $\left(2-3 \min\right.$ at $\left.90^{\circ} \mathrm{C}\right)$ & 15.3 & 13.6 & 13.5 & 61 \\
\hline
\end{tabular}

${ }^{a}$ Two batches, corresponding to two different storage times (beginning and end of controlled atmosphere storage).
764

a limited loss of dietary fiber $(30 \%$, in fresh weight) but a redistribution between the soluble and insoluble fractions. The most important changes occurred during refining and sugaring. Overall, this soluble/insoluble redistribution could affect the effects of dietary fiber in vivo because both types of fiber have different physiological properties, e.g., insoluble fiber influences transit time and soluble fiber delays carbohydrate absorption into the blood.

In the case of pressing/extracting of fruits and the clarification of fruit juices obtained with enzymes (Sharma, Patel, and Sugandha 2017), enzymes degrade fibrous cell walls to facilitate extraction of the juice. Pressing and/or clarifying significantly reduced the dry weight fiber content in juices, up to more than 10-20 times less, as previously shown with apple and orange (Tables 1 and 2).

\section{Carotenoids}

Fruit juices are generally pasteurized to inactivate microorganisms, but this leads to losses of total carotenoids. Alternative processes have been developed, such as pulsed electric field (PEF) (Noci et al. 2008) and high pressure (HP) (Hendrickx et al. 1998). In the study by Cortes et al., PEF $\left(30 \mathrm{kV} / \mathrm{cm}, 100 \mu \mathrm{s}, \approx 40^{\circ} \mathrm{C}\right)$ reduced the total carotenoid content in fresh orange juice by $6.7 \%$, while a reduction of $12.6 \%$ was reached with pasteurization $\left(20 \mathrm{~s}\right.$ at $90^{\circ} \mathrm{C}$ ) (Cortes et al. 2006). During storage at $2{ }^{\circ} \mathrm{C}$, carotenoid stability was better with PEF than with fresh and pasteurized juices. In another study on orange juice, HP strongly increased the total carotenoid content by $45 \%$, while PEF and pasteurization had no effect (Plaza et al. 2011). Following treatments, all orange juices showed good stability upon storage at $4{ }^{\circ} \mathrm{C}$, probably due to vitamin $\mathrm{C}$ that protects carotenoids from oxidation, as confirmed with orange juice enriched with vitamin $\mathrm{C}$ (Choi, Kim, and Lee 2002) and HP orange juice (Bull et al. 2004). The better stability of carotenoids with PEF was also confirmed with other fruit juices, i.e., strawberry and tomato juices (Zulueta et al. 2010).

\section{Vitamin $C$}

Vitamin $C$ is an important and essential nutrient for humans and can be considered an index of the nutritional quality of processes. Vitamin $\mathrm{C}$ is sensitive to heat treatments. Heating, especially during pasteurization or 780 flash pasteurization of fruit juices, is responsible for the 781 degradation of part of the vitamin C.

Among the heat treatments, Santos \& Silva synthesized 783 the data on the retention/degradation of vitamin C in dried 784 fruits using different methods, namely, sun, hot air, micro- 785 waves, osmotic dehydration, freeze-drying and other more 786 marginal techniques (e.g., modified atmosphere drying or 787 low-pressure superheated steam drying) (Santos and Silva 788 2008). The authors conclude that it is possible that not only 789 of ascorbic acid but also several other variables, including 791 fruit characteristics (composition, shape/physical structure, 792 water activity, $\mathrm{pH}$, etc.), making the phenomenon rather 793 complex. Vitamin C losses occur not only during the drying 794

Beyond the "time $\mathrm{x}$ temperature" couple that affects 796 vitamin C content, the concentration of oxygen in the 797 drying atmosphere also influences the final content in the 798 dried product. As reviewed by Santos \& Silva, "various 799 authors have shown the negative effect of oxygen on the reten- 800 tion of vitamin C [...] Consequently, the area exposed to the 801 drying conditions is another factor that affects this nutritional 802 parameter. Increasing the area, the food structure becomes 803 more exposed, and degradation can be enhanced. However, 804 depending on the relation between the area exposed and time, 806 the degradation can be reduced since this increase tends to 807 reduce the drying time." (Santos and Silva 2008).

However, the use of PEF technology at a temperature of 808 less than or equal to $68^{\circ} \mathrm{C}$ causes a lower degradation of vita- 810 min $\mathrm{C}$, especially in orange juice, compared to the degrad- 811 ation with thermal pasteurization (e.g., $95^{\circ} \mathrm{C}$ for 30 seconds) 812 (Buckow, Ng, and Toepfl 2013). Moreover, during storage, 813 the products treated with PEF have higher vitamin C contents 814 than heat-treated juices, i.e., strawberry, tomato and orange 815 juices (Cortés, Esteve, and Frígola 2008; Odriozola-Serrano, 816 Soliva-Fortuny, Gimeno-Añó, et al. 2008). In addition, 817 a significantly higher retention of vitamin C (Elez-Martinez 818 and Martin-Belloso 2007; Min et al. 2003; Qiu et al. 1998) 819 was observed in orange juice treated with $\mathrm{PEF}(35 \mathrm{kV} / \mathrm{cm}, 820$ $59 \mu \mathrm{s}, \approx 60^{\circ} \mathrm{C}$ ) and during refrigerated storage compared to 821 that of thermally treated orange juice $\left(95^{\circ} \mathrm{C}\right.$ for $\left.30 \mathrm{~s}\right)$. It 822 do the drying conditions affect the kinetics of degradation 790 process but also during pre-drying treatments. 796 
should also be noted that the loss of vitamin C during storage is significantly higher than that caused by the treatment (Min, Evrendilek, and Zhang 2007; Moshonas and Shaw 1997). In general, the lower are the treatment time, the intensity of the electric field, the pulse width and the frequency, the better is the retention of vitamin $\mathrm{C}$ in the juices (Elez-Martinez and Martin-Belloso 2007; Isabel OdriozolaSerrano et al. 2007).

Finally, various interactions between vitamin $\mathrm{C}$ and ozone have been reported, notably an increase in vitamin $\mathrm{C}$ content (Ali, Ong, and Forney 2014; Pérez et al. 1999). This increase is likely caused by the inhibition of the activity that has been caused by ozone in several enzymes, such as ascorbate peroxidase and ascorbate oxidase (Ali, Ong, and Forney 2014). In addition, Perez et al. have also suggested that ozone stress can lead to the biosynthesis of vitamin C by using carbohydrate stores (Pérez et al. 1999). In contrast, Alothman et al. detected a decrease in the vitamin $\mathrm{C}$ content of pineapples, bananas and guavas treated with ozone $(8 \pm 0.2 \mathrm{ml} / \mathrm{s}$, exposures for $0,10,20$ and $30 \mathrm{~min}$ at an ozone generation time of $1 \mathrm{~min}$ ) (Alothman et al. 2010). Zhang et al. concluded that higher concentrations of ozone allowed lower retention of vitamin C (Zhang et al. 2005). Therefore, the decrease in vitamin $\mathrm{C}$ may be caused by the induction of ascorbate oxidase activity caused by a high concentration of ozone at harmful concentrations. The vitamin C content therefore depends on the efficiency ratio of its biosynthesis and its oxidation, which can be related to the different reactions of various plants under ozone stress.

\section{Polyphenols}

There is a plethora of literature about the influence of processing on fruit polyphenol contents. It is not within the scope here to review it all. We will only propose the main conclusions.

Fruits are widely recognized as an excellent source of bioactive phenolic compounds. The important polyphenolic constituents in fruits and corresponding juices, in particular apple, pear and grape, can be divided into two groups: phenolic acids such as chlorogenic acid, and flavonoids such as quercetin or catechin. Polyphenols play important roles in the body as antioxidants and/or cellular messengers (Santangelo et al. 2007; Scalbert et al. 2002). Concerning anthocyanins, they are also a widely distributed group of phenolic compounds. Anthocyanins are natural pigments of leaves, petals and fruits that are located in the cell vacuoles, soluble in water, and range from orange-red to purple-blue in the visible spectrum. The pigments are unstable and can be degraded and discolored by many factors, such as $\mathrm{pH}$, temperature, enzymes, oxygen and light. Understanding the mechanism and critical points of anthocyanin destruction by enzymatic activity might be important in the design of an extraction procedure and perhaps in the final formulation of fruit-based foods (Francis and Markakis 1989; Rossi et al. 2003).

Polyphenol yields of juices depend critically on the activity of polyphenol oxidase during processing (Spanos and Wrolstad 1992). Polyphenols degrade, oxidize or polymerize rapidly during processing (including pasteurization) and storage. Heat treatment can cause complex physical and chemical reactions affecting the phenolic composition, including the release of phenolic compounds from their bound forms and the degradation and transformation of phenolic compounds (Nagy, Rouseff, and Lee 1989). Therefore, "the total content of phenolic compounds could be one of the most important indicators of the quality of fruit juices" (page 981) (Chen, Yu, and Rupasinghe 2013). A higher temperature is more effective at controlling bacterial growth; however, it also leads to a greater reduction of phenolic compounds in the juice (Noci et al. 2008). Otherwise, Chen et al. also reported that the duration of treatment is also an important factor affecting phenolic degradation in the juices (Chen et al. 2013), as shown with strawberry juice (Odriozola-Serrano, Soliva-Fortuny, and Martín-Belloso 2008b). However, it has been shown that PEF treatment can achieve an equivalent microbial inactivation efficiency as thermal pasteurization but with much lower phenolic degradation. Therefore, PEF treatment can retain higher levels of phenolic compounds in fruit juices and improve their stability during storage (Buckow et al. 2013; Odriozola-Serrano et al. 2008b; Puértolas, HernándezOrte, Sladaña, Álvarez, and Raso 2010). For detailed data on the degradation of polyphenols by pasteurization or the use of PEF, see the review by Chen et al. (Chen et al. 2013). Otherwise, numerous studies have shown that applications of UV-B irradiation to fruits, such as blueberries (Eichholz et al. 2011) and blackcurrants (Huyskens-Keil, Eichholz, Kroh, and Rohn 2007), may increase the levels of total soluble phenolic compounds in treated products. Finally, published results on the impact of ozone on polyphenol contents are contradictory, with both increased (Ali et al. 2014; Alothman et al. 2010) and decreased (Alothman et al. 2010) contents according to fruit types.

For anthocyanins, it is apparent that their increased retention in fruit following bleaching is attributed to two main factors: the reduction of enzyme-induced anthocyanin degradation, i.e., complete inactivation of native polyphenoloxidase through bleaching, and higher extraction yield related to increased skin permeability of the fruit caused by heat treatment (Kalt, McDonald, and Donner 2000). This has been notably observed on unbleached versus bleached blueberry (Lee, Durst, and Wrolstad 2002; Rossi et al. 2003; Skrede, Wrolstad, and Durst 2000) and its juice (Rossi et al. 2003). However, bleaching alone or in combination with pasteurization has reduced the anthocyanin content of blueberry puree in another study (Brownmiller, Howard, and Prior 2008). At high temperature, the anthocyanin structure is opened to form chalcone, which then degrades into browning products (Francis and Markakis 1989). Other researchers also reported in strawberries and blackberries that the degradation of anthocyanins in concentrates was greater than that of juices (Patras, Brunton, Da Pieve, and Butler 2009). However, in strawberry juice treated with PEF, the anthocyanin content significantly depends on the treatment time (I. Odriozola-Serrano, Soliva-Fortuny, GimenoAñó, et al. 2008). Altuntas et al. further demonstrated that 
the total stability of anthocyanins in Morello cherries was well preserved after PEF treatment $(17-30 \mathrm{kV} / \mathrm{cm}$ for $131 \mathrm{~ms}$ ) (Altuntas et al. 2010), whereas PEF induces a significant loss of cyanidin-3-glucoside in blood oranges and blackberries, and degradation increases as the electric field increases (Zhang et al. 2007). These changes in anthocyanin levels during the shelf life of PEF-treated juices are probably related to the presence of residual enzymatic activities such as $\beta$-glucosidase (Aguiló-Aguayo et al. 2010).

However, reports regarding the effects of ozone on the anthocyanin content are still limited and controversial (Alexandre, Brandao, and Silva 2012; Barth et al. 1995; Pérez et al. 1999). The degradation of anthocyanins is the result of the high oxidation potential of ozone. The effects of irradiation on anthocyanin pigments depend to some extent on the nature of the anthocyanin. For example, diglycosides are relatively stable with respect to monoglycosides vis-à-vis irradiation (Arjeh, Barzegar, and Sahari 2015). Otherwise, water activity is another important factor influencing the stability of anthocyanins during storage (Brønum-Hansen and Flink 1985; Markaris, Livingston, and Fellers 1957). In addition, the presence of oxygen can accelerate the degradation of anthocyanins, either by a direct oxidation mechanism and/or by the action of oxidizing enzymes (Jackman, Yada, and Tung 1987). Beyond enzymatic residual activity, anthocyanin losses in fruits may also be attributed to condensation reactions of anthocyanins with other phenolic compounds (Brownmiller et al. 2008; Chaovanalikit and Wrolstad 2004; A. Hager et al. 2008; T. J. Hager, Howard, and Prior 2008; Ngo, Wrolstad, and Zhao 2007). Overall, greater anthocyanin stability can be achieved by using a lower temperature and short-term heating during processing and storage (Krifi and Metche 2000; RodriguezSaona, Giusti, and Wrolstad 1999).

\section{Influence of processing on the in vitro fruit nutrient bioaccessibility}

Bio-accessibility is defined as the amount of a component that is released from the food matrix in the gastrointestinal tract and therefore available for absorption (Parada and Aguilera 2007). It is usually measured in vitro with artificial digesters. Overall, many studies compare the bio-accessibility of fruit nutrients to each other (depending on the fruit type), but fewer studies have focused on studying the influence of technological processes on the bio-accessibility of bioactive compounds by comparing treated versus untreated fruit.

\section{Thermal treatments}

Thermal treatment can influence the phytonutrient abundance and the formation of degradation compounds, and has implications for the subsequent bio-accessibility of bioactive compounds by affecting the fruit matrix and its microstructure (Barba et al. 2017). Heat treatment may damage the cell walls, making the compounds more accessible for absorption (Barba et al. 2017). There is evidence of positive effects following heat treatments, such as better accessibility of nutrients and/or increased extractability of 1000 bioactive compounds (Barba et al. 2017), e.g., with carote- 1001 noids (Fernandez-Garcia, Rincon, and Perez-Galvez 2008). 1002

In their review, Barba et al. reported the influence of 1003 different thermal and nonthermal treatments on the bio- 1004 accessibility of various hydrophilic and lipophilic bioactive 1005 compounds in vitro (Table 6) (Barba et al. 2017). There 1006 is a trend towards increasing bio-accessibility with PEF 1007 and ultrasound and contrasting effects with HP, while heat 1008 treatments have different effects depending on the 1009 compounds considered. However, Barba et al. did not 1010 analyze all available studies (Barba et al. 2017). So, here is 1011 a brief review of what the other studies report according 1012 to various technological treatments:

\section{Pasteurization} various bioactive compounds of fr various bioactive compounds of fresh, pasteurized or flash-1018 1018 pasteurized orange juice was measured (Aschoff et al. 2015). 1019 The highest concentrations of bio-accessible carotenoids 1020 were observed in pasteurized and flash pasteurized juices. 1021 The bio-accessibility of all carotenoids was significantly 1022 higher in pasteurized juices (37.6 to 39.5\%) than in freshly 1023 squeezed juices (28.3\%) (Aschoff et al. 2015). The heat treat- 1024 ment and finishing (filtering) of the fresh juice increase the 1025 bio-accessibility of lutein, $\beta$-cryptoxanthin, $\alpha$-carotene, and 1026 $\beta$-carotene, while the bio-accessibility of (9Z)-antheraxan- 1027 thin/zeaxanthin decreased from $35 \%$ to $17 \%$ and $16 \%$ in 1028 pasteurized and flash pasteurized juices, respectively 1029 (Aschoff et al. 2015). According to the authors, "The insig- 1030 nificant change in carotenoid bio-accessibility from the flash 1031 pasteurized to the pasteurized juice indicates a "saturation" 1032 of these processing effects, meaning that further heating 1033 or finishing beyond such an "optimum processing" does not 1034 further improve carotenoid bio-accessibility" (page 584).

In comparison with this study, Stinco et al. reported 1036 a higher relative uptake of carotenoid from in vitro digests in 1037 industrially pressed and finished juice (up to 52\%) than in 1038 freshly squeezed juice (34\%) and pasteurized industrial juice 1039 (40\%) (Stinco et al. 2012). According to their study, juice fin- 1040 ishing causes a reduction in particle size, thus improving the 1041 release of carotenoids, while thermal pasteurization apparently 1042 decreased the release of carotenoids during digestion. In con- 1043 trast, the production of pasteurized orange juice significantly 1044 increases the stability of vitamin $\mathrm{C}$ during digestion, generat- 1045 ing a residual level of 78\% compared to that of the test food: 1046 approximately $70 \%$ for fresh and flash-pasteurized juices. 1047 Finally, no difference was observed in the bio-accessibility of 1048 flavonoids for the three juices.

\section{Freezing, freeze-drying, microwaves and drying}

In the study by Dalmau et al., in vitro gastric digestion of 1053 fresh, frozen $\left(-196^{\circ} \mathrm{C}\right.$ in liquid nitrogen), lyophilized 1054 $\left(-50^{\circ} \mathrm{C}\right.$ and $\left.30 \mathrm{~Pa}\right)$ and convection dried $\left(60^{\circ} \mathrm{C}\right.$ and $\left.2 \mathrm{~m} / \mathrm{s}\right) 1055$ Granny Smith apples was followed (Dalmau et al. 2017). 1056 First, compared to unprocessed apples, the microstructure 1057 and composition of apples changed with all treatments, 1058 
leading to behavioral changes during gastric digestion, e.g, faster decreases in soluble solids. Freezing and lyophilization led to decrease in the polyphenol content and antioxidant activity of apples before and during gastric digestion. Conversely, convective drying increased the initial polyphenol content and antioxidant activity of apples, but they decreased during gastric digestion. On the contrary, raw apples showed minor decreases in total polyphenol content and antioxidant activity during gastric digestion, and greater retention of polyphenols and antioxidants (Dalmau, et al. 2017).

As an alternative to conventional heat treatments such as pasteurization, which can destroy some vitamin $\mathrm{C}$ and alter sensory or organoleptic properties, ultra-freezing (direct immersion in liquid nitrogen) can be a less damaging alternative treatment. Stinco et al. therefore investigated different thawing methods (microwaves, refrigeration, and room temperature) of ultra-frozen orange juice on the levels and bio-accessibility of carotenoids and antioxidant activity (Stinco et al. 2013). Briefly, microwave thawing significantly affected the carotenoid content and antioxidant activity, and led to the highest relative bio-accessibility percentages for carotenoids with provitamin A activity compared to those of the other thawing methods.

In the last study by Kamiloglu et al., to evaluate the in vitro bio-accessibility of fresh and sun-dried figs, the total antioxidant capacity, the total pro-anthocyanidin content and the main phenolic compounds were determined at different phases of simulated gastrointestinal digestion (Kamiloglu and Capanoglu 2013). The main results showed that dried figs had increased bio-accessibility of proanthocyanidins and chlorogenic acid as well as antioxidant capacity. In addition, the bio-accessibility of anthocyanins decreases with sun-drying.

According to Ryan and Prescott, "pasteurization can potentially increase antioxidant capacity by causing slight changes in the structure of the antioxidant compounds, which in turn makes them more stable to $p H$ change, allowing the antioxidant activity to continue increasing after the gastric phase of the in vitro digestion process" (page 1195) (Ryan and Prescott 2010). This theory comes from Cevallos-Casals and Cisneros-Zevallos (2004) and Kammerer et al. (2004) who found that acylated anthocyanins were more stable to $\mathrm{pH}$ and temperature changes. In addition, the antioxidant activity appears stabilized by boiling, probably because of the inactivation of prooxidant enzymes at elevated temperatures (Gazzani et al. 1998).

\section{Nonthermal treatments}

According to Barba et al., nonthermal treatments can be used as tools to facilitate the release of micronutrients and bioactive compounds from the plant matrix during the digestion process (Table 6) (Barba et al. 2017):

\section{Mechanical: pressing for juices, purées and nectars}

The first study compares the bio-accessibility of bioactive compounds of orange or mandarin pulp/juice (De Ancos et al. 2017). The bio-accessibility of the bioactive compounds (hesperidin, narirutin, total flavonoids, total phenols and ascorbic acid) and the antioxidant activity of the bio-accessible fraction were higher in the pulp of oranges and mandarin than those in the corresponding juices. Thus, according to the authors, the consumption of pulp compared to the same portion of fruit juice would confer a better supply of bioactive compounds and antioxidant activity (De Ancos et al. 2017). In another study, Rodrogo et al. showed conflicting results according to citrus type (Rodrigo et al. 2015). Thus, in Navel Cara Cara orange, bioactive carotenoids in freshly hand-squeezed juice exhibited a higher relative bio-accessibility than in pulp, while the opposite was observed for Clementine mandarins, especially for $\beta$-cryptoxanthin.

In another study with citrus fruits, the concentrations of all carotenoids (lutein, zeaxanthin, zeinoxanthine, $\beta$-cryptoxanthin) in supernatants and micelles were higher after in vitro digestion for orange juice compared to concentrations in un-pressed fresh fruit (Aschoff et al. 2015a). In addition, the bio-accessibility of the total carotenoids is $6.3 \%$ and $27.5 \%$, and the bio-accessibility of $\beta$-cryptoxanthin is $4.9 \%$ and $25.9 \%$ for the orange and the corresponding juice, respectively. The same research team then studied the in vitro bio-accessibility of carotenoids, flavonoids and vitamin $\mathrm{C}$ from segments of orange, a mashed orange homogenate, the corresponding juice (pressed by hand) and then pasteurized or flash-pasteurized (Aschoff et al. 2015b). The presence of a fibrous matrix during in vitro digestion was assumed to significantly reduce the total bio-accessibility of all carotenoids of fresh fruit (12\%) compared to juices (29-30\%). However, the mechanical destructuration of orange segments in the mash before digestion did not alter the bio-accessibility of the carotenoids. The differences are even more pronounced for total flavonoids since nearly $90 \%$ is bio-accessible in juices, and only approximately $20 \%$ is in segments or homogenates of orange. For vitamin $\mathrm{C}$, juice pressing increases its bio-accessibility from approximately $55-70 \%$.

In a completely different way, an in vitro simulation of human digestion and uptake was applied to sour cherry and corresponding nectar (Toydemir et al. 2013). The main finding of this work is that recovery of total anthocyanins obtained from the dialyzable fraction of the nectar sample is five times higher on a fresh weight basis (13 times on a dry weight basis) than recovery obtained for the dialyzable fraction of the fruit sample, that could be related to greater anthocyanin stability in the nectar matrix (Toydemir et al. 2013). The nectar samples in this study contain more than 50\% added sucrose, and high fruit sugar concentrations have been reported to maintain and stabilize anthocyanins (Wrolstad et al. 1990).

Finally, Ryan and Prescott studied the evolution of the antioxidant potential of fruit juices (15 fresh and 10 from concentrates with a long shelf life) before and after in vitro digestion (Ryan and Prescott 2010). Overall, for many of the juices, the total antioxidant capacity was significantly increased after in vitro digestion. A possible explanation is that the heat treatment destroys the cell wall, allowing more antioxidant components to be released, and resulting in 
Table 6. Impact of thermal and non-thermal treatments on the bioaccessibility of lipophilic and hydrophilic compounds in fruit products (adapted from Barba et al. (2017) with permission of Elsevier(C).

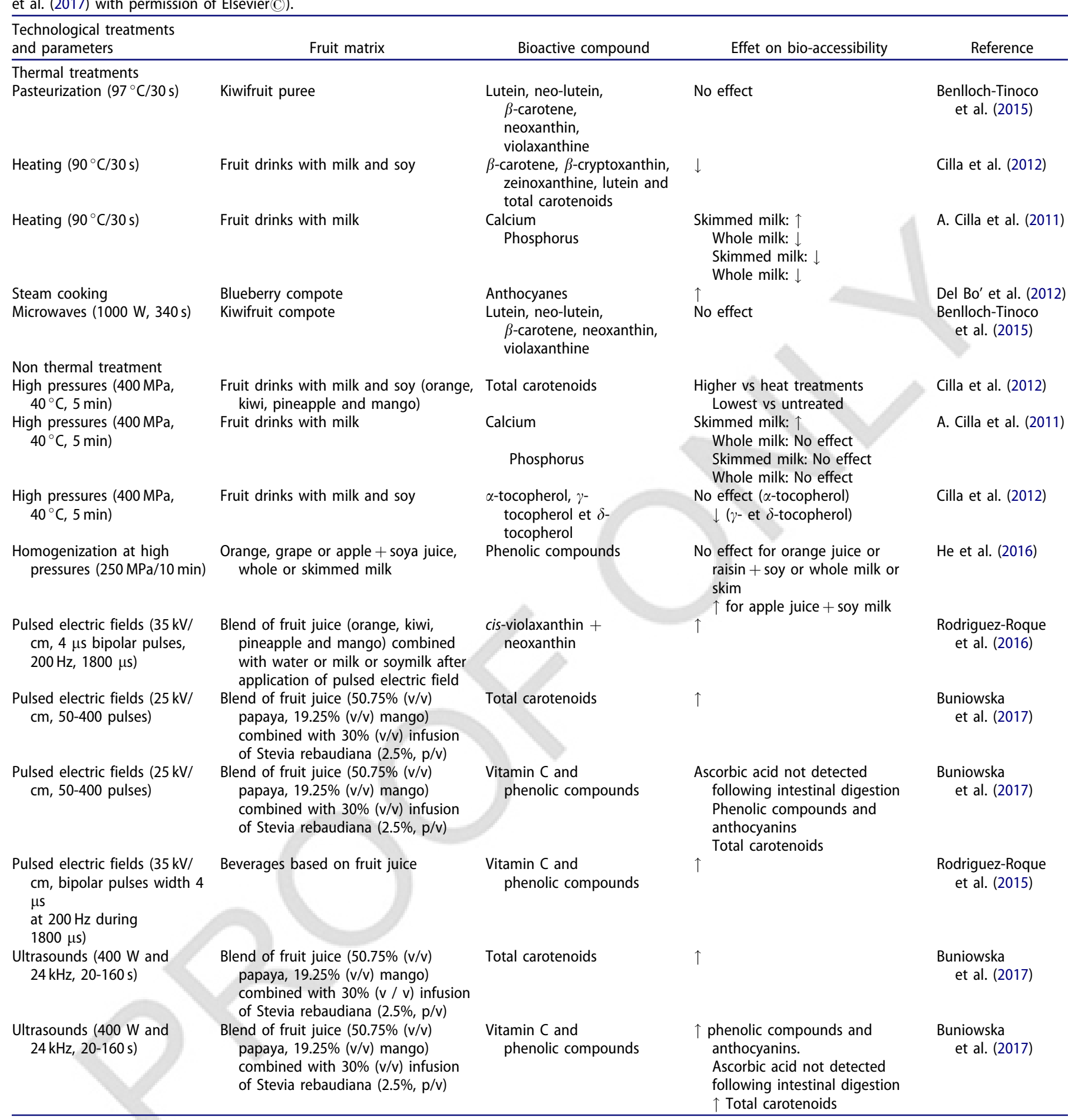

a greater antioxidant capacity (Dewanto, $\mathrm{Wu}$, and Liu 2002; Dewanto et al. 2002; Jeong et al. 2004; Takeda et al. 2003).

\section{High pressure}

Briones-Labarca et al. studied the effect of HHP on the bioaccessibility of specific nutrients (antioxidants, minerals and starch) in apple and established the conditions of the process that maximize health benefits (Briones-Labarca et al. 2011). The apple was pressurized at $500 \mathrm{MPa}$ for $2,4,8$ and 10 minutes. The antioxidant potential of the apple increases during digestion and with the duration of the application of HHP. It is possible that changes in the matrix of fibrous tissues induced by HHP, for example, cell wall destructuring, resulted in the release of compounds with antioxidant action (Briones-Labarca et al. 2011). The HHP also increased the available contents in the apple before digestion from $2 \% 1288$ $(500 \mathrm{MPa} / 10 \mathrm{~min})$ to $303 \%$ (500 MPa/8 min) for calcium, 1289 $5-11 \%$ for iron and 9-29\% for zinc depending on the appli- 1290 cation time. However, the dialyzability and solubility of cal- 1292 cium, iron and zinc, compared to the values of untreated 1293 apples, were reduced by HHP. According to the authors, 1294 
"This indicates that the bio-accessibility of these minerals, especially calcium, is not necessarily dependent on its concentration in the apple" (page 526). In addition, the digestible starch fraction increases with the duration of application of HHP.

In conclusion, Barba et al. (77) recalled, "The action of HP is based on a decrease in molecular volume changes, which may induce chemical reactions and physical transformations. This compression of the volume seems to be highly effective in modifying the integrity of cell walls and membranes (Patterson 2014), thus promoting the extractability of the intracellular bioactive compound and facilitating its solubilization" (Barba et al. 2017). "Thus, it is likely that HP facilitates the release of lipophilic compounds through plant cell disruption, resulting in increased bio-accessibility of carotenoids". They concluded that, "the type and strength of the cell wall depend on the type of fruit and vegetables, and in turn the pressure-induced cell disruption depends on the pressure level and may be the reason for the different results reported on bio-accessibility of carotenoids" (Barba et al. 2017).

\section{Pulsed electric fields}

The studies reported by Rodríguez-Roque et al. (2016) and Buniowska et al. (2017) showed that the transformation of fruit juices by PEF positively affects the bio-accessibility of carotenoids (Table 6). Since considerable cell disruption is expected due to chopping and pressing of the fruits, the increase is apparently obtained by improvements induced by PEF in the enzymatic activity.

In their review, Barba et al. explained that the phenomenon of electroporation, a direct consequence of an electrical "break", could be the main factor responsible for the modification of bio-accessibility (Barba et al. 2017). This phenomenon allows the perforation of the cytoplasmic membrane, favoring the escape of the cellular contents and probably the solubilization and digestion.

\section{Ultrasound}

The effects of ultrasound have not been extensively studied. Basically, ultrasound yields microbubbles (in the liquid) that develop but finally collapse, favoring the formation of shock waves (Barba et al. 2017). These shock waves generate high temperatures and pressures leading to cavitation, which affects cell walls and membranes (Cravotto and Binello 2016). As reviewed by Barba et al. (2017), ultrasound promotes cell wall disruption, facilitating, for example, the release of bound carotenoids or the extractability of carotenoids by promoting the breakdown of the carotenoid-protein binding (Buniowska et al. 2017; Cravotto and Binello 2016).

\section{Storage and ripening}

The storage of fruits, and therefore ripening during this period, can influence the bio-accessible fractions of bioactive compounds, as evidenced by the following studies:

Mandarin storage for 5 weeks at $12{ }^{\circ} \mathrm{C}$ increases the bioaccessibility of bioactive compounds (ascorbic acid, phenolic acids and total flavonoids) (De Ancos et al. 2017). Similarly,
Schulz et al. showed that acai berries (or Juçara) had higher antioxidant activity after digestion, and increased bio-accessibility of various phenolic and flavonoid acids between 42 and 69 days of ripening after red berries appeared on the branches (Schulz et al. 2017).

For starch-rich bananas, the degree of ripening plays an important role in the bio-accessibility and digestibility of starch to glucose. Vatanasuchart et al. compared the hydrolysis indexes of three varieties of banana at different stages of maturity: green, yellow-green and ripe bananas (Vatanasuchart, Butsuwan, and Narasri 2015). The results are contradictory: while one variety (Mali-ong) has a slightly lower in vitro hydrolysis index for ripe banana compared to that of green banana, the opposite is observed for the other two varieties (Khao-nuan and Laong-nam).

Cilla et al. have also shown that cold storage $\left(2-4{ }^{\circ} \mathrm{C}\right)$ for 135 days of fruit juice made from orange and grape concentrates and apricot puree (with added sucrose) increases the antioxidant capacity in the course of gastrointestinal digestion in vitro (+ 20-59\%) (Antonio Cilla et al. 2011). According to the authors, "this improvement in antioxidant capacity could be explained, at least in part, by the release of bound antioxidants (mainly polyphenols) from the food matrix by the action of digestive enzymes in the small intestine" (page 91).

Finally, Ornelas-Paz et al. were interested in the impact of the mango ripening stage (light, moderate and complete) on the in vitro bio-accessibility of $\beta$-carotene (Ornelas-Paz et al. 2008). The authors reported that the amount of $\beta$-carotene transferred to the micellar fraction during simulated digestion increased significantly as the fruit ripened, probably due to qualitative and quantitative changes that occur in pectin from mango pulp during ripening, and that influenced micellarization of $\beta$-carotene.

\section{Influence of processing on the fruit antioxidant potential}

\section{In vitro}

Antioxidant levels of fruit products have been reported by Carlsen et al. among more than 3100 foods and food ingredients (Carlsen et al. 2010). These tables are the most complete to date, and they give values for different degrees of fruit processing (Table 7). Based on median values, plant products are on average 9 times richer in antioxidants than animal products. Among plant products, fruits are a significant source of antioxidants, especially given their high-water content. Among fruits, berries are the richest in antioxidants, with a maximum of $34.5 \mathrm{mmol} / 100 \mathrm{~g}$ for dog rose berries. Regarding the influence of processing, fruit and juices have similar median values of $0.7-0.8 \mathrm{mmol} / 100 \mathrm{~g}$. Drying increases the antioxidant content with a median value of $2.4 \mathrm{mmol} / 100 \mathrm{~g}$, mainly due to the loss of water. Canned fruits have a fairly high median antioxidant content of $2.0 \mathrm{mmol} / 100 \mathrm{~g}$. One of the possible explanations is that the appertisation releases antioxidant polyphenolic molecules (the bound forms become free) within the fruits, making them accessible to the assays. Despite refining, due to the loss of water, jams have a higher median value than fresh 
Table 7. Median antioxidant content of different fruit products acccording to the degree of processing (adapted from Carlsen et al. (2010)).

Antioxidant content $(\mathrm{mmol} / 100 \mathrm{~g})$

\begin{tabular}{lc}
\hline Plant-based products & $0.9(\mathrm{n}=1943)$ \\
Animal-based products & $0.1(\mathrm{n}=211)$ \\
Plant- and animal-based products & $0.3(\mathrm{n}=854)$ \\
Berries and derived products & $9.9(\mathrm{n}=119)$ \\
Fruits and fruit juices & $1.3(\mathrm{n}=278)$ \\
Fresh fruits & $0.8(\mathrm{n}=40)$ \\
Dried fruits & $2.4(\mathrm{n}=17)$ \\
Fruit juices & $0.7(\mathrm{n}=10)$ \\
Canned fruits & $2.0(\mathrm{n}=7)$ \\
Jams & $1.1(\mathrm{n}=4)$ \\
Red wine & $2.5(\mathrm{n}=1)$ \\
White wine & $0.3(\mathrm{n}=1)$ \\
Fruit sirups & $2.4(\mathrm{n}=4)$ \\
Fruit-base sweetened beverages & $0.1(\mathrm{n}=13)$ \\
Mango sorbet & $0.1(\mathrm{n}=1)$ \\
&
\end{tabular}

fruit, i.e., $1.1 \mathrm{mmol} / 100 \mathrm{~g}$. Fruit sirups also concentrate antioxidants to a median value of $2.4 \mathrm{mmol} / 100 \mathrm{~g}$. Fermentation of grapes into red and white wine gives a median antioxidant content of $1.4 \mathrm{mmol} / 100 \mathrm{~g}$, similar to that of fresh grapes. Finally, sweetened fruit-based beverages have the lowest antioxidant levels, i.e., $0.1 \mathrm{mmol} / 100 \mathrm{~g}$.

Other authors have measured the antioxidant potential of fruit products, especially for different fresh fruits ( $\mathrm{Li}$ et al. 2011; Miller et al. 2000; Pellegrini et al. 2006); however, the use of different chemicals for the antioxidant assays makes it difficult to compare with the exhaustive and systematic study of Carlsen et al. (2010). Pellegrini et al. showed that among the dried fruits tested in their study, prunes have the highest antioxidant potential (Pellegrini et al. 2006), in agreement with the more recent study by Chang et al. (Chang, Alasalvar, and Shahidi 2016). Miller et al. confirmed that berries are much richer in antioxidants than other fruits by $+68 \%$ (Miller et al. 2000). Among fruits other than berries, they also report that plums are 22 times richer in antioxidants than watermelons - the least rich (Miller et al. 2000) - which is very close to the results of Carlsen et al. (20 times richer) (Carlsen et al. 2010). For Li et al., pomegranate, plum and guava are among the richest antioxidant fruits, berries aside, and the antioxidant capacities of the 62 fruits tested are significantly correlated with polyphenol levels ( $\mathrm{Li}$ et al. 2011). This significant correlation was also shown for 18 nontraditional tropical fruits from Brazil (Rufino et al. 2010), 11 more traditional fruits (Sun et al. 2002), and for different fruit juices $(n=36)$ (Borges, Mullen, and Crozier 2010), but not more than $9 \%$ for citrus-type traditional fruits (Sun et al. 2002), probably because vitamin C could importantly contribute to the antioxidant potential. This correlation is also found between the polyphenol concentration and antioxidant potential of several applesauces (Oszmianski et al. 2008). More generally, the vitamin C content of fruits is not very significantly correlated with the antioxidant potential (Proteggente et al. 2002). Finally, Wang et al. calculated that most of the antioxidant capacity of fruits comes from the juice fraction and that the contribution of the fruit's pulp fraction to the total antioxidant activity of a fruit is generally less than 10\% (Wang, Cao, and Prior 1996).
Various studies have reported antioxidant activities of 1472 dried fruits (e.g., peaches and dates), which are always 1473 higher than those of their corresponding fresh equivalents 1474 (Ishiwata et al. 2004; Rababah, Ereifej, and Howard 2005; 1475 Threlfall, Morris, and Meullenet 2007; Vinson et al. 2005), 1476 obviously because antioxidants are concentrated after the 1477 dehydration process, as has been shown with six fresh and 1478 dried fruits (apricot, plum, cranberry, grape, fig and date) 1479 (Vinson et al. 2005). However, on a dry matter basis, the 1480 drying process can significantly reduce the polyphenol con- 1481 tent in the fruit (Vinson et al. 2005). For dried fruits, hydro- 1482 philic antioxidants account for more than $94 \%$ of the total 1483 antioxidant activity (Wu et al. 2004). However, dried fruits 1484 have a higher antioxidant potential than vitamins $\mathrm{E}$ and $\mathrm{C} 1485$ taken alone (Vinson et al. 2005).

Otherwise, the influence of thermal (cooking, bleaching, 1487 drying, osmotic dehydration, and extrusion-cooking) and non- 1488 thermal (PEF, radiation, dense phase carbon dioxide, ozone, 1489 and edible coating) treatments on fruit antioxidant potentials 1490 has been extensively and comprehensively studied in several 1491 other specific and original articles. We cannot review all of 1492 them here. A good summary of the effect of nonthermal treat- 1493 ments can be found in the review by Xue et al. (2016).

The results of these studies are very complex, sometimes with seemingly contradictory data that may be due to variation in different factors: (i) type, variety and degree of maturity of the fruit; (ii) number of technological treatments undergone (thermal, nonthermal, mechanical, additions of ingredients and/or additives, etc.) each with a particular action on each antioxidant (hydrophilic and lipophilic); (iii) variation of the parameters for the same treatment (pressure, temperature, duration, concentrations, etc.); (iv) various antioxidant tests used; and (v) generation, at the same time as degradation, of antioxidant compounds during certain treatments. Table 8 summarizes the effects (trends) of the different technological treatments applied to the fruits on the antioxidant potential. In their review dedicated to the effects of processing on the phenolic antioxidants of fruits and vegetables, Nayak et al. also offer some relevant and recent conclusions (Nayak, Liu, and Tang 2015, 143155):

i. "It is apparent that complex mixtures of phytochemicals rather than a single antioxidant in foods are responsible 1515 for health benefits because of their additive and/or 1516 synergistic effects. It would be biased to measure the 1517 antioxidant activity of fruits solely on the basis of the 1518 presence of vitamin $C$ or any individual antioxidant 1519 compound in the raw or processed food" (page 911); 1520

ii. "The role and contribution of water in the processed 1521 foods has not been investigated thoroughly for the 1522 measurement of antioxidant activity. Depending on the 1523 type of processing technique with different mediums of 1524 heating, the total antioxidant activity could be underes- 1525 timated in regards to the quantity of water present in 1526 the processed foods" (page 912);

iii. "High temperature treatments can have detrimental 1528 effects on the phenolics and flavonoids, thereby reducing 1529 the antioxidant activities of processed fruits" (page 912); 1530 


\section{Thermal}

Generic

Cooking \& bleaching

Drying, dehydration, freeze-drying ...

1538

1539

1540

\section{Radiations (ionizing or non-ionizing)}

Ultrasounds

Supercritical $\mathrm{CO}_{2}$

Ozone

Mecanical treatments ( \pm thernar) Peeling Juice pressing ( \pm added sugars)

Nectar production

Jam production Storage

- Short: $\downarrow$ by degradation of natural antioxidants and $\uparrow$ antioxidant compounds of the Maillard reaction

- Long: $\downarrow$ then $\uparrow$ by production of antioxidant brown compounds of the Maillard reaction

- Bleaching: $\uparrow$ by increased extraction of polyphenols

- Canned: $\uparrow$ by increased extraction of polyphenols

- Air/sun drying: $\uparrow$ by water losses and $\downarrow$ by oxidation of antioxidant compounds

- Freeze-drying: preserves antioxidant capacity better than conventional drying Vacuum microwaves $>$ freeze-drying $>$ air drying

- $\downarrow$ by leaching soluble water compounds (e.g. phenolics) to the osmotic solution

- The use of high concentrations of osmotic solution promotes greater retention of antioxidant capacity

- ? Lack of studies

- High pressure treatments on fruit products depend on food matrices and treatment parameters (pressure, time and temperature) and methods of analysis of antioxidant activity

- $\leftrightarrow$ No marked effect but lack of studies

- The intensity of the electric field, the pulse width, the pulse frequency, the polarity of the pulse, the processing time, or the shape of the pulse are among the most important parameters of high intensity pulsed electric fields affecting enzymatic inactivation, antioxidant activity and anthocyanin content: - Retention of antioxidant capacity increases as the width and frequency of the pulse increase

- Bipolar treatments are much more useful than monopolar treatments in maintaining antioxidant activity

- $\uparrow$ by increasing the polyphenol content

- Reduces phenolic losses during storage

- The effect may depend on the intensity of the radiation

- G-rays seem to be better at controlling antioxidant activity than ultraviolet

- $\downarrow$ by degradation of polyphenols (types anthocyanins): oxidation reaction promoted by interaction with free radicals formed during sonication + temperature rise

- $\uparrow$ by increasing soluble phenolic compounds and decreasing antioxidant losses during storage

- Higher pressure results in higher inactivation of polyphenol oxidase

- Prevents possible losses of other antioxidant compounds such as anthocyanins and b-carotene

- Lack of information on the behavior of phytonutrients other than vitamin $C$ and carotenoids, and polyphenols taken individually

- $\uparrow$ by increasing phenolic and carotenoid compounds: ozone induces oxidative stress in the fresh product when it comes into contact with the plant tissue and induces various physiological responses, including the synthesis of antioxidants

- $\downarrow$ by loss of antioxidant polyphenols in the skin

- Without added sugars: $\leftrightarrow$ No marked effect

- With added sugars: $\downarrow$ by dilution effect with added sugar

- $\downarrow$ by dilution effect with added sugar

- $\downarrow$ by degradation of polyphenols and dilution with added sugar

- Stability then $\uparrow$ in long term: the formation of polymeric compounds during storage compensate for the loss of antioxidant capacity due to the degradation of the monomeric anthocyanins

iv. "Degradation of higher molecular weight phenolics to lower phenolic compounds with potential antioxidative activity during various food processing operations could be compensating the overall antioxidant activity of processed foods" (page 912);

v. "Research focusing on optimization of thermal and nonthermal food processing operations has potential to retain phytochemicals in the processed foods" (page 912).

\section{In humans}

If there are many intervention studies on the impact of the consumption of various fruits on the antioxidant capacity of the blood (or urine) in humans, very few have examined the influence of the transformation of the same fruit on this potential. In addition, there is no study on compotes and canned fruits.

However, the review by Serafini and Peluso may give a first general overview of the influence of different fruitbased products on antioxidant potentials in humans (Mauro Serafini and Peluso 2017). The authors went beyond fruit juices and synthesized intervention studies $(n=23)$ in humans regarding fruits, fruit juices, fermented fruits, freeze-dried fruits and extracts of fruits. Within the limits of the biomarkers used in these studies, no study reported an increase in oxidative stress in the subjects tested, regardless of their health status. Regarding fruit juices, seven out of eight studies show an improvement in the antioxidant status and one no effect; for fermented papaya, there is either no effect (two studies) or an improvement (two studies); for dried/freeze-dried fruit, there is either no effect (two studies) or an improvement (three studies); and for fruit extracts, four studies show no effect and three an improvement. Of all the forms of fruit tested, the juices seem particularly effective, also suggesting a higher bioavailability of antioxidant compounds from juices following extraction.

In an earlier meta-analysis based on 16 intervention studies, Tonin et al. reported that there was no significant difference between fruit juice and placebo for plasma total antioxidant capacity (TEAC assay), superoxide dismutase and catalase levels (Tonin et al. 2015). However, the juices were superior to controls in improving the blood level of vitamin $\mathrm{C}$ and in reducing the level of malondialdehyde. In addition, Lettieri-Barbato et al. showed, on the basis of a meta-analysis including eighty-eight intervention studies (both acute and chronic), that fresh and dried fruit (only in 
acute), red wine (both chronic and acute) and fruit juices (only in acute) significantly increased plasma nonenzymatic antioxidant capacity (NEAC) (Lettieri-Barbato et al. 2013). A review by Chang et al. discusses phytochemicals, antioxidant efficiencies and the potential health benefits of eight traditional dried fruits such as apples, apricots, dates, figs, peaches, pears, prunes and raisins and dried cranberries (Chang et al. 2016). On the basis of five intervention studies, the authors report an improvement in antioxidant status in humans with various dried fruits (Cao et al. 1998; Parker et al. 2007; Rankin et al. 2008; Valentová et al. 2007; Vinson et al. 2005).

The consumption of fruit products can also be accompanied by the consumption of dairy products. It is believed that the antioxidant properties of the dietary phenolic compounds of fruits are reduced in vivo because of their affinity for milk proteins (M. Serafini, Ghiselli, and Ferro-Luzzi 1996; Spencer et al. 1988). The study by Serafini et al. was conducted to provide some answers to this question (Serafini et al. 2009), and the researchers showed in healthy volunteers that the consumption of a fruit rich in antioxidants, such as blueberry, in combination with whole milk decreases its ability to increase plasma endogenous antioxidant defenses and to deliver bioactive molecules, such as caffeic acid, into the blood circulation.

\section{Influence of processing on the fruit alkalinizing potential}

All foods that are eaten give rise in the blood and in the extracellular fluid to acids and bases. The PRAL index measures the acidifying or alkalizing potential of foods in relation to the PRAL of this food (Remer and Manz 1995). It is in the urine that one obtains the measurement of this charge. This scientific measure therefore does not cover the entire phenomenon of acid-base balance in the human body. Although this index is often used in food dietetics, there is no scientific consensus on the consequences of its use for human health. The PRAL index therefore remains indicative of a potentiality. The formula for the PRAL index is as follows:

$$
\begin{gathered}
\text { PRAL }(\mathrm{mEq})=[0.49 \mathrm{P} \text { tein }(\mathrm{g})]+[0.037 \mathrm{xphosphorus}(\mathrm{mg})] \\
-[0.021 \text { xpotassium }(\mathrm{mg})]-[0.026 \mathrm{xmagnesium}(\mathrm{mg})] \\
-[0.013 \mathrm{xcalcium}(\mathrm{mg})]
\end{gathered}
$$

Positive values indicate an acidifying potential, negative values indicate an alkalizing potential, and a zero result indicates neutrality. Acidifying foods or "acid producers" generate more acids than bases. These foods are mainly animal proteins (meat, fish, eggs, and dairy products). Their metabolism leads to strong acids such as hydrochloric acid, sulfuric acid, phosphoric acid or uric acid. However, cereals, especially when they are refined, also produce acids. Basifying or alkalizing foods generate more bases than acids. These foods are basically fruits and vegetables. Neutral foods $(\mathrm{PRAL} \approx 0)$ have no influence on the acid-base balance. These foods are, for example, vegetable oils and refined sugars. It is advisable to maintain a good balance between acidifying and alkalizing foods, since an excess of acids can 1708 contribute to health problems with age.

Most fruit-based products are alkalizing, except for some 1710 complex processed dairy-based compositions (yogurt on a 1711 fruit bed, light fruit yogurt, brewed fruit yogurt, strawberry 1712 sundae) and desserts (apple pie), mainly based on citrus 1713 (e.g., lemon sherbet and lemon custard), which are slightly 1714 acidifying (Table 9). Dried fruits are the most alkalizing, 1715 probably because of the loss of water that concentrates the 1716 compounds involved in the calculation of the PRAL. Of the 1717 fresh fruits, bananas are the most alkalizing and citrus fruits 1718 the least. Of the processed fruit, candied fruit is the most 1719 alkalizing, followed by fruit juice, fermented fruit (alcohol), 1720 canned fruits and fruit sirup. Complex fruit-based products 1721 are almost neutral, probably because of the higher levels of 1722 sugar and fat. The median value of the PRAL indexes for 1723 fruit products decreases with the degree of processing, from 1724 dried fruits to fruit desserts. This decrease is related to the 1725 PRAL formula, which suggests that the more fruit products 1726 are processed the less they are notably rich in potassium, 1727 magnesium and calcium, or even richer in phosphorus, with 1728 the protein content playing quite little because fruits contain 1729 only minor little amounts of protein.

\section{Influence of processing on the fruit glycemic} potential

The different fruits contain a highly varied mixture of 1735 glucose, fructose and sucrose, with each of these three 1736 simple sugars having its own glycemic index (Foster-Powell, 1737 Holt, and Brand-Miller 2002). Technological transformation, 1738 by releasing intrinsic sugars as extrinsic sugars and adding 1739 free sugars through the addition of sweeteners, can therefore 1740 modify the glycemic responses of fruits in humans. In this 1741 section, the influence of technological transformations on 1742 the glycemic indexes of fruit products will be analyzed 1743 according to two approaches: from officially published glycemic index tables and from original studies of the scientific literature.

\section{From glycemic index tables}

Table 10 presents the glycemic indexes obtained from 1751 studies in humans of fruit products according to their 1752 degree of transformation. All data are extracted from the 1753 glycemic index tables of Foster-Powell et al. published in 1754 2002 (Foster-Powell et al. 2002). Note that no glycemic 1755 index data could be found for fruit compotes.

With few exceptions, overall fruit products have low 1757 $(<55)$ to moderate (55-70) glycemic indexes. Processed 1758 fruits (with added sugars) have a slightly higher median gly- 1759 cemic index than minimally processed fruit products 1760 (approximately +9 ). Among the fresh fruits, there are large 1761 variations, with the extremes being cherry (glycemic index- 1762 $=22$ ) and watermelon (glycemic index $=72$ ). Canned fruits 1763 are placed in the intermediate range (38 for canned peaches) 1764 and juices a little higher (50 for orange juice), but the data 1765 are less numerous. Concerning dried fruits, they tend to 1766 
Table 9. Alkalizing potential of fruit-based products according to their degree of processing (adapted from Piquet (Piquet 2012)).

\begin{tabular}{|c|c|c|c|c|c|}
\hline Raw/dried fruits & PRAL index & Processed fruits & PRAL index & Cor@f fruit-based products & PRAL index \\
\hline Dried banana & -27.5 & Candied pineapple & -18.4 & Biculc with figs & -1.8 \\
\hline Dried apricot & -21.7 & Candied fig & -10.5 & Citrus beverage & -1.0 \\
\hline Raisins & -21.0 & Candied pear & -10.1 & Orange sorbet & -0.9 \\
\hline Dried fig & -18.1 & Passion fruit juice & -5.7 & Grenadine sirup & -0.6 \\
\hline Dried litchi & -16.3 & Candied apricot & -5.0 & Light yogurt on fruit bed & -0.4 \\
\hline Prunes & -13.4 & Prunes in sirup & -4.0 & Light sugar sorbet & -0.4 \\
\hline Dried date & -11.9 & Rhubarbe compote & -3.8 & Lemonade & -0.1 \\
\hline Raw plantain banana & -9.6 & Canned apricot & -3.5 & Orange soda & -0.1 \\
\hline Cooked plantain banana & -9.2 & Mandarin juice & -3.4 & Lemon lemonade & -0.1 \\
\hline Banana & -6.9 & Candied cherries & -3.4 & Natural yoghurt on fruit bed & 0 \\
\hline Guava & -6.8 & Grapefruit juice & -3.1 & Lemon sorbet & +0.1 \\
\hline Black grapes & -6.1 & Orange juice without added sugars & -2.9 & Lightened fruit yoghurt & +0.1 \\
\hline Orange zest & -5.6 & Orange and grapefruit juice & -2.9 & Apple pie & +0.1 \\
\hline Kiwifruit & -5.6 & Tropical fruit salad (canned) & -2.8 & Sundae (strawberry) & +0.2 \\
\hline Papaya & -5.5 & Cider & -2.5 & Brewed fruit yogurt & +0.4 \\
\hline Cassis & -5.2 & Grape juice & -2.5 & Biscuit tray with fruit pulp & +1.0 \\
\hline Melon & -5.1 & Lemon juice & -2.4 & Lemon custard & +4.5 \\
\hline Fig & -4.9 & Sweet cider & -2.4 & & \\
\hline Grenade & -4.8 & Red wine & -2.4 & & \\
\hline Passion fruit & -4.6 & Apple vinegar & -2.3 & & \\
\hline White grape & -4.5 & Sugar free apple juice & -2.2 & & \\
\hline Apricot & -4.3 & Plum with sirup & -2.2 & & \\
\hline Currant & -4.2 & Peach with sirup & -2.0 & & \\
\hline Reine-Claude plum & -4.1 & Sweet wine & -1.8 & & \\
\hline Grapes & -3.9 & Rosé wine & -1.8 & & \\
\hline Guigne cherry & -3.8 & Pear with sirup & -1.7 & & \\
\hline Mirabelle & -3.8 & Blackberry with sirup & -1.6 & & \\
\hline Mango & -3.3 & Canned cherries & -1.6 & & \\
\hline Peach & -3.1 & Fruits with sirup (canned) & -1.6 & & \\
\hline Nectarine & -3.1 & Wine vinegar, balsamic vinegar & -1.6 & & \\
\hline Mandarin & -3.1 & White wine & -1.5 & & \\
\hline Orange & -3.0 & Fruit salad (canned) & -1.4 & & \\
\hline Cherry & -3.0 & Apricot jam & -1.2 & & \\
\hline Blackberry & -2.8 & Light jam & -1.2 & & \\
\hline Plum & -2.6 & Dry white wine & -1.2 & & \\
\hline Strawberry & -2.5 & Fruit jelly & -1.1 & & \\
\hline Raspberry & -2.4 & Maraschino cherries & -1.0 & & \\
\hline Litchi & -2.4 & Orange marmelade & -1.0 & & \\
\hline Pineapple & -2.3 & Sparkling white wine & -1.0 & & \\
\hline Lemon & -2.3 & Sugar free fruit juice & -1.0 & & \\
\hline Grapefruit & -2.3 & Fruit paste & -0.9 & & \\
\hline Asian pear & -2.2 & Sweet dried cranberry & -0.8 & & \\
\hline & & Papaya nectar & -0.8 & & \\
\hline & & Peach nectar & -0.7 & & \\
\hline & & Pear nectar & -0.3 & & \\
\hline Median value & -4.1 & Median value & -2.0 & Median value & -0.1 \\
\hline
\end{tabular}

have highly variable glycemic indexes, from 31 for dried apricots to 103 for dried dates. There is no obvious explanation for these extreme values.

The effect of the degree of fruit processing on their glycemic index results from both the "composition" and "matrix" effects (Fardet and Rock 2018). Concerning the "composition" effect, remember that the fruits contain a mixture of glucose (glycemic index $=100$ ), fructose (glycemic index $=19$ ) and sucrose (glycemic index $=68$ ). Thus, fructose is partly responsible for the low glycemic index of fruit products, which slightly distorts the interpretation of the indexes because fructose metabolization follows a different route than glucose, notably via the small intestine and liver (Jang et al. 2018). Thus, high levels of fructose (especially when added as fructose sirup resulting from the hydrolysis of cornstarch) in complex fruit products can lower the glycemic index, giving a "misleading" image of a positive health potential of the product while excess fructose is harmful to health (Ha et al. 2015). Concerning the loss of the "matrix" effect, the transformation of fresh fruits into juices, jams or marmalades ( \pm added sugars) does not seem to have any marked effects on a potential increase in the glycemic index. Even if juice processing does increase the glycemic index, it is not very significant, except for grapefruit (whole fruit index $=25$ and juice index $=48$ ) and orange (whole fruit index $=42$, unsweetened juice index $=50$ and marmalade index $=48$ ).

In 1998, Wills et al. studied the "composition" effect of fruits $(n=15)$ and vegetables $(n=9)$ to explain the variations in their glycemic indexes (Wills, Miller, and Matawie 1998). They found that the glycemic index of different fruits and vegetables varies from simple to triple, but no causal explanation of the differences has been advanced. This study examined the statistical relationship between published data on the glycemic index and nutrient levels in twenty-four fresh fruits and vegetables. The most significant relationships were a reduced glycemic index with an increase in organic acids, particularly malic acid, and the monosaccharides glucose and fructose, and an increase in the glycemic index with an increase in minerals. There was no significant correlation with sucrose, starch, citric acid, proteins, fats or vitamin C. The glycemic index is reduced by changes in 
Table 10. Glycemic index of fruit-based products according to their degree of processing (adapted from Foster-Powell et al. (2002)). ${ }^{\text {a }}$

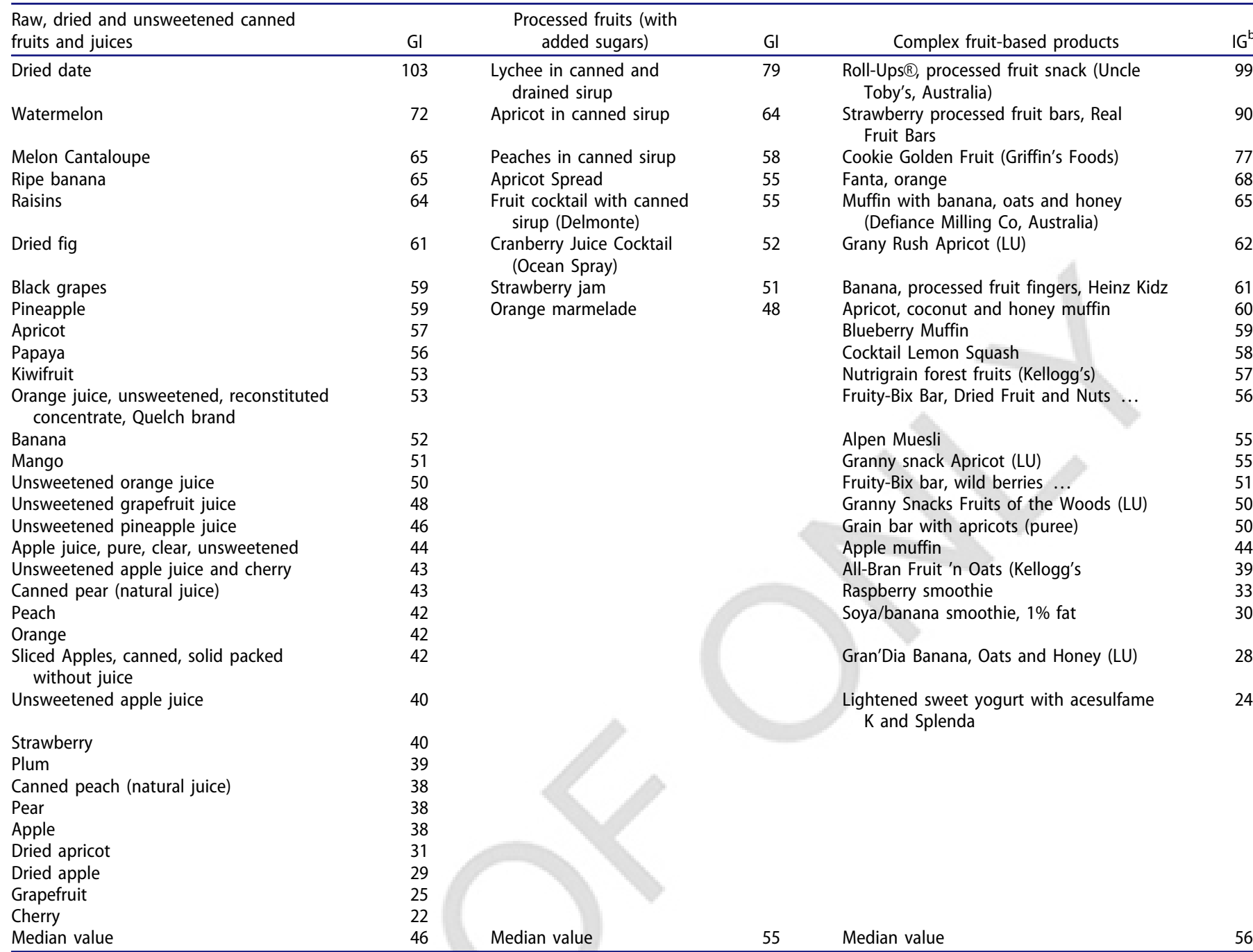

${ }^{a}$ The glycemic index values are given with reference to a glucose test solution (glycemic index $=100$ ).

${ }^{\mathrm{b}}$ Includes fruit products combined with dairy and/or cereal ingredients. Gl, Glycaemic Index.

composition that increase the osmolality and nutrient concentration, thus delaying gastric emptying. It is also suggested that acidity per se, i.e., $\mathrm{pH}$, can have a direct effect on the glycemic index.

Previously, the glycemic index of apples, pears and kiwifruits was compared to their levels of total sugars and sugar compounds ( $\mathrm{Ha}$ et al. 1992). Positive correlations between the glycemic index and total sugars and sugary compounds of kiwifruits were found $(r=0.7)$, but no such association was observed for apples and pears. The authors concluded that this suggests that some components of apples and pears inhibit the direct relationship between the sugar content of apples and pears and their glycemic index.

\section{From original articles}

Many studies have been dedicated to measuring glycemic responses following the consumption of different whole fruits, and many of these results have been included in the glycemic index tables of Foster-Powell et al. (2002). We will not review the data. However, studies measuring the impact of a technological process on the glycemic response of fruits are rare.

\section{The "matrix" effect}

In a pioneering study, Haber et al. showed in ten healthy subjects that the whole apple was less hyperglycemic and hyperinsulinemic than applesauce derived from these same fruits and that it was less so than an apple juice from these same fruits (Haber et al. 1977). This study thus highlighted the "matrix" effect of the fruits, where the state of destructuration (and thus of transformation) of the matrix increases from the whole apple to the juice, passing from a solid texture for the whole fruit, to viscous (or semisolid) for applesauce, and finally to liquid for the juice. It is also well known that a solid texture is more satiating than a semisolid texture and that a semisolid texture is more satiating than a liquid texture (Chambers 2016). These results were 1998 confirmed in 2017 in the study by Tey et al., who compared 1999 the effects of two fruit shapes (guava and papaya pieces and 2000 compote) on glycemic responses (Tey, Lee, and Henry 2017) 2001 in nineteen healthy adults and elderly subjects. All these 2002 
fruit products had low glycemic indexes, below 50, but compotes gave significantly higher indexes (index $=42-47$ ) than fruit pieces (index $=29-38$ ).

The same type of result is also found in Bolton et al. in healthy volunteers where consumption of orange leads to a lower insulin response than orange juice and a lower postabsorptive glucose drop (Bolton, Heaton, and Burroughs 1981). However, with whole grapes, the insulin response was paradoxically higher than with grape juice. According to the authors, glucose in grapes is more insulinogenic than in apples and oranges. Conversely, grape juice leads to less pronounced insulinemia, probably because its high osmolality delays gastric emptying. However, diluting the juice does not increase its insulinogenicity. Additionally, the glycemic and insulinemic responses of the fruits seem to depend on both the fiber and glucose contents.

As noted in the study by Haber et al. (1977) technological treatments can modify the glycemic index of fruit products, especially following the destructuration of the food matrix. Thus, in the study by Jimenez et al., the glycemic index of the fruit of the peach palm (Bactris gasipaes), cooked $\left(96^{\circ} \mathrm{C}\right.$ for 30 minutes) or in the form of chips, and of the fruit pulp of the dragon fruit (or pitahaya) were measured in 12 healthy adults (Jimenez, Gomez, Perez, and Blanco-Metzler 2012). The average value of the glycemic index is 48 for pitahaya pulp and 35 for cooked peach palm fruit, which can be classified as low glycemic index foods. The glycemic index of the chips is 60 , corresponding to a food with a moderate glycemic index. Processing for the production of chips has therefore caused an increase in the value of the glycemic index compared to the cooked fruit, probably, according to the authors, because the grinding, molding and cooking stages favored the availability of starch during hydrolysis by digestive enzymes.

The peeling of fruits can also influence the glycemic index. Additionally, Katsilambros et al. studied the influence of pear and apple peel on the glycemic response (Katsilambros et al. 1985) in twenty-seven diabetic patients. No significant difference was observed in terms of mean blood glucose and serum insulin among the two meals (skinned or skinless fruit). Peeled and unpeeled fruit appear to produce the same hyperglycemia in type 2 diabetic subjects, despite the high fiber content of the skin.

Finally, Elizondo-Montemayor et al. studied the effects of HHP treatment of fresh mango puree on the glycemic indexes and postprandial glycemic responses of thirty-eight healthy Mexican subjects in a cross-randomized clinical trial; this type of new treatment is supposed to preserve the nutritional qualities of the mango, in particular the glycemic index (Elizondo-Montemayor et al. 2015). The average glycemic index for mango puree treated at HHP was significantly lower (index $=33$ ) than untreated mangoes (index $=43$ ). The viscosity and solubility values of HHP-processed mango puree samples were significantly higher, which influenced the glucose peak $\left(\mathrm{T}_{\max }\right)$ at 45 minutes and induced lower AUC values by $20 \%$ compared to untreated mangoes. The results of this study support the interest in the use of HHP treatment to reduce the glycemic index of fruits.

\section{Fruits with added sugars}

2062

The impact on the glycemic index of adding sugars to fruit juices is another issue of interest. Wilson et al. tested the impact of drinking unsweetened cranberry juice (low calorie, $19 \mathrm{cal} / 240 \mathrm{~mL}$ ), and that sweetened with dextrose (normal calories, $120 \mathrm{cal} / 240 \mathrm{~mL}$ ) compared to a control isocaloric drink (water with sugar, 19 and $120 \mathrm{cal} / 240 \mathrm{~mL}$ ) on the glycemic and insulinemic responses in 12 subjects with type 2 diabetes (Wilson, Meyers et al. 2008). The main results showed that the addition of dextrose considerably increases the glycemic response of a fruit juice. In another study published the same year, Wilson et al. observed the same types of results with cranberry juice sweetened with high fructose corn sirup, i.e., a higher glycemic concentration 30 minutes after consumption, although the differences are no longer significant after 180 minutes, as well as for the insulin response (Wilson, Singh, et al. 2008).

The last study concerns strawberry jam made with either sugar (sucrose), sugar and corn sirup, sugar and glucose, polydextrose (synthesized from dextrose and sorbitol), apple juice or maltitol (sweetener), consumed alone or with bread (Kurotobi et al. 2010). For jams without bread, the glycemic indexes calculated for thirty healthy subjects are 51 (sucrose), 74 (corn sirup), 70 (sugar + glucose), 47 (apple juice) and 17 (polydextrose). There was also a high correlation $(r=0.969, p=0.006)$ between the actual glycemic index and the glycemic index calculated from the sugar composition of the jams. In the presence of bread, the differences are less clear.

\section{Influence of processing on the fruit satiety potential}

\section{All fruit-based products}

In 1995, Holt et al. measured, through a subjective assessment of satiety on a scale of $1-5$, the satietogenic potential of 38 common foods divided into six food groups in 11-13 healthy subjects per group (Holt et al. 1995). They were able to define an index of satiety, with index 100 being the reference index of white bread. The groups "Protein-rich foods" (index of average satiety $=170 \pm 13$ ), "Carbohydrate-rich foods" (166 \pm 24$)$ and "Fruits" (170 \pm 19$)$ are on average the most satietogenic of the six groups, above Breakfast cereals with milk, Snacks and Confectionery, and various Bakery products. Whole fresh fruits therefore appear satietogenic, at equivalent levels with porridge or whole pasta. From these data, we developed the Fullness Factor $(\mathrm{FF})^{\mathrm{TM}}$, which allows for a quick assessment of the satietogenic potential from the composition of the food (SELF Nutrition Data 2014):

$$
\begin{aligned}
\mathrm{FF}^{\mathrm{m}}= & \operatorname{MAX}\left(0.5, \operatorname{MIN}\left(5.0,41.7 / \mathrm{CAL}^{0.7}+0.05 \mathrm{XPR}\right.\right. \\
& \left.\left.+6.17 \mathrm{E}^{-4} \mathrm{X} \mathrm{DF} 3-7.25 \mathrm{E}^{-6} \mathrm{X} \mathrm{TF} 3+0.617\right)\right)
\end{aligned}
$$

where CAL is the calories per $100 \mathrm{~g}$ ( 30 minimum), PR is the grams of protein per $100 \mathrm{~g}$ (maximum 30), DF is the grams of dietary fiber per $100 \mathrm{~g}$ (12 maximum), and $\mathrm{TF}$ is the grams of fat per $100 \mathrm{~g}$ ( 50 maximum). The FF reasonably predicts the satiety responses given by Holt et al. for 38 foods (Holt et al. 1995). FF values range from 0 to 5. Foods 
Table 11. Median satietogenic potential of fruits according to degree of processing (based on NOVA classification). ${ }^{\text {a }}$

\begin{tabular}{lc}
\hline NOVA Groups & $\mathrm{FF}$ \\
\hline Group $1(\mathrm{n}=68):$ Un-/minimally-processed & 3.37 \\
Group $3(\mathrm{n}=28):$ Processed & 2.99 \\
Complex fruit-based foods $(\mathrm{n}=28):$ processed/ultra-processed & 1.64 \\
\hline
\end{tabular}

${ }^{\mathrm{a} F F}$ are calculated from from French Ciqual Data (ANSES-Afssa 2008). FF, Fullness Factor.

with a high FF are more likely to satisfy hunger with fewer calories. Low FF foods are less likely to satisfy hunger.

From the ANSES-Ciqual database, the FF of 124 fruitbased products could have been calculated according to the degree of processing (ANSES-Afssa 2008). The median results are presented in Table 11. Unsurprisingly, mainly because of a higher fiber content and secondarily due to a lower calorie content, the un-/minimally processed fruits have the highest indexes of satiety (median $\mathrm{FF}=3.37$ ), followed by processed fruits $(\mathrm{FF}=2.96)$ and complex fruit-based foods (including various desserts) $(\mathrm{FF}=1.87)$. In detail, carambola, rhubarb and fig are the most satietogenic $(\mathrm{FF}>4.50)$ fruit products in the un-/minimally processed group; lemonade, fruit nectars and carbonated fruit beverages in the processed group; and sweetened fermented yogurt in the last group. As expected, the fruit-based products in the last group with the lowest FF generally have the highest densities of calories and lipids (e.g., chocolate bar with dried fruit, fruit shortbread, strawberry pie, etc.).

\section{Whole fruits versus compotes versus juices}

Coming back to the pioneering study of Haber et al. on apple, compote and apple juice conducted with ten healthy adult subjects, the feeling of satiety 30 minutes postprandial was clearly the highest for the apple, followed by the compote, and then the apple juice (Haber et al. 1977). This difference between the three products lasted until an hour and thirty minutes after consumption and thus reveals the importance of the integrity of the food matrix on the feeling of satiety. In the same vein, Flood-Obbagy and Rolls tested in fifty-eight healthy adult subjects how the consumption of apples in different forms before lunch (apple, applesauce and apple juice with and without added fibers) influences the satiety and energy intake 15 minutes after lunch (FloodObbagy and Rolls 2009). The results showed that apple consumption significantly reduced dietary energy intake from lunch (preload + test meal) by $15 \%$ ( $187 \mathrm{kcal}$ ) compared to that in controls and reduced energy intake compared to applesauce and two apple juices. Satiety scores significantly differed after apples were consumed in different forms (apple $>$ applesauce $>$ both juices $>$ control) (Flood-Obbagy and Rolls 2009), and adding natural levels of fiber to the juice did not improve satiety. According to a similar experimental design, Houchins et al. studied the effects of the shape of the food (solid fruit versus liquid, $400 \mathrm{kcal}$ ) consumed before a meal on the feeling of satiety that follows just after this meal in fifteen healthy adults and nineteen overweight or obese adults (Houchins et al. 2013). The solid fruits tested were apples, red grapes, and apples and raisins, while liquid foods were apple and grape juices. Appetite 2180 assessments were also obtained before and after eight 2181 weeks of increasing fruit and vegetable consumption $(20 \% 2182$ of estimated energy needs). The main results showed 2183 that "Acute post-ingestive appetitive responses were weaker 2184 following consumption of fruits in beverage versus solid food 2185 forms" and that "consumption of beverage or solid fruit and 2186 vegetable food loads for 8 weeks did not chronically alter 2187 appetitive responses". Mourao et al. also studied the influence 2188 of the shape of the food (watermelon versus watermelon 2189 juice, cheese versus milk, and pulp versus coconut water) on 2190 the daily energy intake in one hundred twenty obese and 2191 healthy adults (Mourao et al. 2007). The total daily energy 2192 intake was significantly higher, at 12,19 and 15\%, on days 2193 when the liquid forms of food were ingested, i.e., water- 2194 melon, coconut and milk/cheese, respectively. According to 2195 the authors, these results showed that "Food rheology exerts 2196 an independent effect on energy intake. Dietary compensation 2197 for beverages is weaker than for solid food forms of 2198 comparable nutrient content. Thus, they pose a greater risk 2199 for promoting positive energy balance". These conclusions 2200 were also supported by an older study carried out in healthy 2201 volunteers consuming grapes or oranges (Bolton et al. 1981), 2202 where the feeling of satiety was greater after eating whole 2203 fruits than in the form of juice and the return of appetite 2204 was delayed (Bolton et al. 1981).

Finally, Moorhead et al. tested the level of carbonation 2206 (none, medium and high) of an orange juice drink (also 2207 containing added sucrose, citric and ascorbic acid) on satiety 2208 and food and short-term energy intake in thirty healthy 2209 subjects (Moorhead et al. 2008). Compared with the low 2210 carbonation beverage, the consumption of medium and high 2211 carbonation drinks ten minutes before consuming an ad 2212 libitum lunch led to a significantly higher satiety until lunch 2213 when dietary and energy intake were significantly lower. 2214 There were no significant effects on satiety after eating or 2215 food intake for the rest of the day.

\section{Conclusions and perspectives}

As a first conclusion, the scarcity of human studies 2220 that address the following issue has to be emphasized 2221 "How does a the following issue has to be emphasized: 2222 "How does a change in fruits by processing modify the 2222 physiological parameters such as the antioxidant status, 2223 weight gain, and glycemic and lipemic responses?"

\section{Is there a "process" effect for the fruit's} health potential?

In most cases, a fruit product is the result of several 2230 treatments, often including both thermal and mechanical 2231 treatments - even fermenting in some cases - followed by 2232 storage. In addition, each of the treatments influences each 2233 of the individual fruit compounds differently. This double 2234 complexity of "compounds X treatments" makes it difficult 2235 to develop general laws on the influence of processes on the 2236 health potential of fruit treatment by treatment. However, 2237 if one again takes the simplified NOVA classification of 2238 
un-/minimally processed, processed and ultra-processed fruits, one can begin to see some interesting and significant tendencies emerging (Table 12):

\section{Un-/minimally processed fruits}

Un-/minimally processed fruit-based products have a high nutritional density of bioactive compounds, but their digestive bio-accessibility remains limited because of the fibrous walls of the cells in which the compounds are "trapped". However, the scientific evidence that would prove that increased fruit nutrient bio-accessibility is desirable for health are lacking. The partial loss of this "matrix" effect with thermal, physical or mechanical treatments in added sugar-free compotes, purées and juices improves the bioaccessibility, and increases the glycemic index in parallel, which is less desirable. In addition, the antioxidant, alkalizing and satietogenic potentials of un-/minimally processed fruits are high, making them food products with high FHP.

\section{Processed fruits}

These are mainly fruit products with added sugars. The "matrix" effect is obviously altered because of the thermal and mechanical treatments, as with compotes, nectars and juice without added sugars, but it can still be well preserved in products such as "fruits in sirup" or "tinned fruits". The addition of sugars decreases and dilutes the nutritional density in protective bioactive compounds, tends to increase the glycemic index, and decreases the antioxidant, satietogenic and alkalinizing potentials.

\section{Ultra-processed fruits}

These products are mainly recombinant complex products incorporating fruit preparations and sodas and sirup/fruit juice-based drinks. Their nutritional properties have been significantly altered, including a loss of the "matrix" effect and a change to "red" of all nutritional indicators, except for the bio-accessibility, which can be increased for some bioactive compounds, but what are the health benefits if this only concerns a minor fraction of the initial bioactive compounds?

\section{Which processes should be favored?}

The analysis of the literature suggests that new nonthermal treatments such as HP or PEF could have advantages over more traditional treatments, such as thermal treatments in particular. There is indeed an increase in antioxidant potential, an increase in some phytonutrient levels and significantly lower losses of vitamin C.

The addition of sugar is quite common in fruit preparations, especially in compotes, juices, marmalades and jams. Sugar is not very satisfying and dilutes the nutrient density of fruits in phytonutrients, especially antioxidants. It can also increase the glycemic index (glucose) and promote insulin resistance (glucose and fructose) and reduce the alkalizing potential of fruits. Products without added sugar

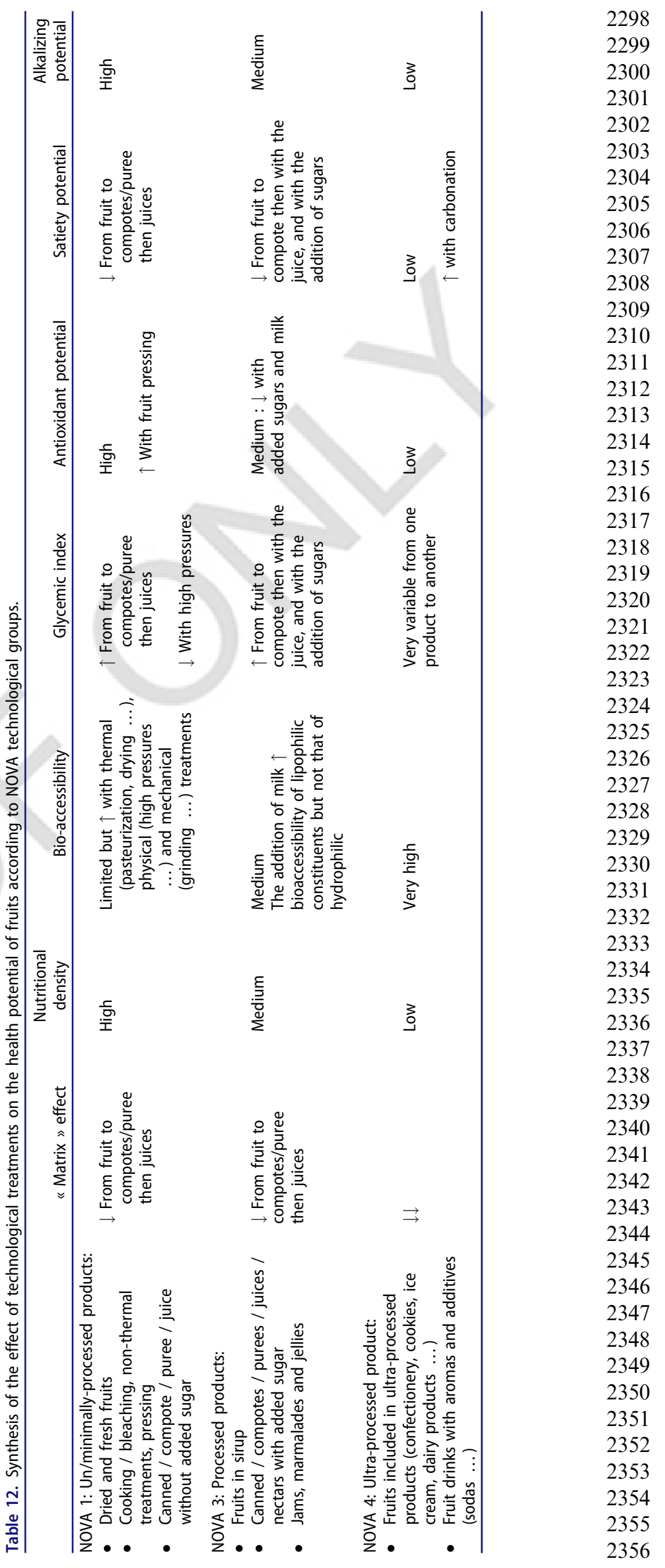


are therefore preferred, or at least replacing white refined sugar by nutrient-dense whole sugar.

Mechanical treatments (peeling, grinding, and pressing) tend to reduce the health potential of the fruits due to loss of the "matrix" effect (on the satiety), an increase in the bioavailability of the sugars, and losses of fiber and antioxidant polyphenols. However, they can also increase the digestive bio-accessibility of certain bioactive compounds by destructuring the fibrous walls, in particular that of carotenoids.

\section{Are these effects true regardless of the types of fruit?}

It is difficult to answer this question because the data are not sufficient, especially in view of the great diversity of existing fruits. In the scientific literature, berries and citrus have been well studied. Berries are particularly rich in anthocyanins and antioxidants, which makes it necessary to be vigilant about their transformation to preserve this important nutritional property as much as possible. However, since fruits tend to have common botanical properties - except perhaps banana, which are quite different the rules regarding treatments seem to be quite applicable to all types of pulp fruit (pome or stone fruits).

\section{"5 Fruits and vegetables a day"?}

Although " 5 fruits and vegetables a day" is a well-known nutritional recommendation, in view of the results reviewed here, it would be relevant to precisely state "preferably minimally processed". Fresh or dried fruits have the highest FHP in all respects: they are satietogenic, high in fiber and protective bioactive compounds, have moderate glycemic indexes, are rather alkalizing and are rich in antioxidants. Any treatment applied, involving storage, inevitably begins to diminish these potentials. The real issue is therefore to limit this decrease.

Intermediate fruit products such as, first, fruit purées and $100 \%$ fruit juice without added sugars, and, second, jams, fruits in sirup or canned fruits may be nutritionally interesting alternatives because they retain a part of their health potential, but it is altered by both a more or less important loss of the "matrix" effect and the loss or dilution of bioactive compounds.

\section{Research gaps}

This exhaustive review about the impacts of processing on fruit health potential has raised some research gaps. Notably, as regards with the crucial of food matrix on fruit health potential, more interventional studies are needed to study the "matrix" effect of fruit-based products, especially through interventional studies. In addition, results about the effect of processing on GI remains contradictory, notably due to the presence of fructose. Therefore, more studies are also needed to investigate - beyond the fructose content how fruit matrix disintegration through processing may affect fruit-based product GI, e.g., in whole fruits, fruit compote and purees and fruit juices. Finally, epidemiological studies take too little into account the processing effect on 2416 the risk of metabolic deregulation and chronic diseases asso- 2417 ciated with fruit-based products consumption.

\section{Disclosure statement}

Céline Richonnet is a registered pediatric dietician nutritionist and has 2422 been the Nutrition Director of the MOM Group since 2017. Anthony 2423 Fardet worked as a consultant for the MOM Group between July 20172424 and May 2018.

\section{Abbreviations}

FF Fullness Factor 2428

FHP Food Health Potential 2429

GI Glycemic Index 2430

HHP Hydrostatic High Pressure 2431

PEF Pulsed Electric Field 2432

PRAL Potential Renal Acid Load 2433

Funding

This work was supported by the MOM Group, a leading company in 2436 fruit purees.

\section{ORCID}

Anthony Fardet (D) http://orcid.org/0000-0003-4972-9217

\section{References}

Aguiló-Aguayo, I., R. Soliva-Fortuny, and O. Martín-Belloso. 2010. 2445 Impact of high-intensity pulsed electric field variables affecting per- 2446 oxidase and lipoxygenase activities of watermelon juice. LWT - Food 2447 Science and Technology 43 (6):897-902. doi: 10.1016/j.lwt.2010.01. 2448 022

Alexandre, E. M. C., T. R. S. Brandao, and C. L. M. Silva. 2012 microbial load reduction and quality retention of strawberries. 2451 Journal of Food Engineering 108 (3):417-26. doi: 10.1016/j.jfoodeng. 2452 2011.09.002.

Ali, A., M. K. Ong, and C. F. Forney. 2014. Effect of ozone pre-condi- 2454 tioning on quality and antioxidant capacity of papaya fruit during 2454 ambient storage. Food Chemistry 142 (Supplement C):19-26. doi: 10. 2455 1016/j.foodchem.2013.07.039.

Alothman, M., B. Kaur, A. Fazilah, R. Bhat, and A. A. Karim. 2010. 2457 Ozone-induced changes of antioxidant capacity of fresh-cut tropical 2458 fruits. Innovative Food Science \& Emerging Technologies 11 (4): 2459 666-71. doi: 10.1016/j.ifset.2010.08.008.

Altuntas, J., G. A. Evrendilek, M. K. Sangun, and H. Q. Zhang. 2010. 2460 bial inactivation of sour cherry juice. International Journal of Food 2462 Science \& Technology 45 (5):899-905. doi: 10.1111/j.1365-2621.2010. 2463 02213.x.

ANSES-Afssa, Ciqual (Centre d'information sur la qualité des ali- 2465 ments). 2008. Table CIQUAL. Composition nutritionnelle des ali- 2465 ments. Accessed May 28, 2019. http://www.afssa.fr/TableCIQUAL/.

Arjeh, E., M. Barzegar, and M. A. Sahari. 2015. Effects of gamma 2467 irradiation on physicochemical properties, antioxidant and microbial 2468 activities of sour cherry juice. Radiation Physics and Chemistry 114: 2469 18-24. doi: 10.1016/j.radphyschem.2015.05.017. Carle, and R. M. Schweiggert. 2015a. Bioavailability of beta-cryptox- 2471 anthin is greater from pasteurized orange juice than from fresh 2472 oranges - a randomized cross-over study. Molecular Nutrition \& 2473 Food Research 59 (10):1896-904. doi: 10.1002/mnfr.201500327. 
Aschoff, J. K., S. Kaufmann, O. Kalkan, S. Neidhart, R. Carle, and R. M. Schweiggert. 2015. In vitro bioaccessibility of carotenoids, flavonoids, and vitamin $\mathrm{C}$ from differently processed oranges and orange juices citrus sinensis (L.) osbeck. Journal of Agricultural and Food Chemistry 63 (2):578-87. doi: 10.1021/jf505297t.

Barba, F. J., L. R. B. Mariutti, N. Bragagnolo, A. Z. Mercadante, G. V. Barbosa-Canovas, and V. Orlien. 2017. Bioaccessibility of bioactive compounds from fruits and vegetables after thermal and nonthermal processing. Trends in Food Science \& Technology 67:195-206. doi: 10.1016/j.tifs.2017.07.006.

Barth, M. M., C. Zhou, J. Mercier, and F. A. Payne. 1995. Ozone storage effects on anthocyanin content and fungal growth in blackberries. Journal of Food Science 60 (6):1286-8. doi: 10.1111/j.1365-2621. 1995.tb04575.x.

Benlloch-Tinoco, M., A. Kaulmann, J. Corte-Real, D. Rodrigo, N. Martinez-Navarrete, and T. Bohn. 2015. Chlorophylls and carotenoids of kiwifruit puree are affected similarly or less by microwave than by conventional heat processing and storage. Food Chemistry 187 :254-62. doi: 10.1016/j.foodchem.2015.04.052.

Bolton, R. P., K. W. Heaton, and L. F. Burroughs. 1981. The role of dietary fiber in satiety, glucose, and insulin - studies with fruit and fruit juice. The American Journal of Clinical Nutrition 34 (2):211-7. doi: 10.1093/ajcn/34.2.211

Borges, G., W. Mullen, and A. Crozier. 2010. Comparison of the polyphenolic composition and antioxidant activity of European commercial fruit juices. Food \& Function 1 (1):73-83. doi: 10.1039/ c0fo00008f.

Brat, P., and B. Cuq. 2007a. Transformation et conservation des fruits Perte de la structure initiale. Techniques de l'ingénieur Filière de nroduction: produits d'origine végétale. Base documentaire: IB433DUO (ref. article: f6273)

Brat, P., and B. Cuq. 2007b. Transformation et conservation des fruits Préservation de la structure initiale. Techniques de l'ingénieur Filière de production: produits d'origine végétale. Base documentaire: TIB433DUO (ref. article: f6272)

Bremer, A. A., P. Auinger, and R. S. Byrd. 2009. Relationship between insulin resistance-associated metabolic parameters and anthropometric measurements with sugar-sweetened beverage intake and physical activity levels in US adolescents findings from the 1999-2004 National Health and Nutrition Examination Survey. Archives of Pediatrics \& Adolescent Medicine 163 (4):328-35. doi: 10.1001/archpediatrics.2009.21.

Briones-Labarca, V., G. Venegas-Cubillos, S. Ortiz-Portilla, M. Chacana-Ojeda, and H. Maureira. 2011. Effects of high hydrostatic pressure (HHP) on bioaccessibility, as well as antioxidant activity, mineral and starch contents in Granny Smith apple. Food Chemistry 128 (2):520-9. doi: 10.1016/j.foodchem.2011.03.074.

Brønum-Hansen, K., and J. M. Flink. 1985. Anthocyanin colourants from elderberry (Sambucus nigra L.). 3. Storage stability of the freeze dried product. International Journal of Food Science \& Technology 20 (6):725-33. doi: 10.1111/j.1365-2621.1985.tb01970.x.

Brownmiller, C., L. R. Howard, and R. L. Prior. 2008. Processing and storage effects on monomeric anthocyanins, percent polymeric color, and antioxidant capacity of processed blueberry products. Journal of Food Science 73 (5):H72-H9. doi: 10.1111/j.1750-3841.2008.00761.x.

Buckow, R., S. Ng, and S. Toepfl. 2013. Pulsed electric field processing of orange juice: a review on microbial, enzymatic, nutritional, and sensory quality and stability. Comprehensive Reviews in Food Science and Food Safety 12 (5):455-67. doi: 10.1111/1541-4337.12026.

Bull, M. K., K. Zerdin, E. Howe, D. Goicoechea, P. Paramanandhan, R. Stockman, J. Sellahewa, E. A. Szabo, R. L. Johnson, C. M. Stewart. 2004. The effect of high pressure processing on the microbial, physical and chemical properties of Valencia and navel orange juice. Innovative Food Science \& Emerging Technologies 5 (2):135-49. doi: 10.1016/j.ifset.2003.11.005.

Buniowska, M., J. M. Carbonell-Capella, A. Frigola, and M. J. Esteve. 2017. Bioaccessibility of bioactive compounds after non-thermal processing of an exotic fruit juice blend sweetened with Stevia rebaudiana. Food Chemistry 221:1834-42. doi: 10.1016/j.foodchem. 2016.10.093.
Cao, G., S. L. Booth, J. A. Sadowski, and R. L. Prior. 1998. Increases in human plasma antioxidant capacity after consumption of controlled diets high in fruit and vegetables. The American Journal of Clinical Nutrition 68 (5):1081-7. doi: 10.1093/ajcn/68.5.1081.

Carlsen, M. H., B. L. Halvorsen, K. Holte, S. K. Bøhn, S. Dragland, L. Sampson, C. Willey, H. Senoo, Y. Umezono, C. Sanada, et al. 2010 The total antioxidant content of more than 3100 foods, beverages, spices, herbs and supplements used worldwide. Nutrition Journal 9 (1):3. doi: 10.1186/1475-2891-9-3.

Cevallos-Casals, B. v A., and L. Cisneros-Zevallos. 2004. Stability of anthocyanin-based aqueous extracts of Andean purple corn and redfleshed sweet potato compared to synthetic and natural colorants. Food Chemistry 86 (1):69-77. doi: 10.1016/j.foodchem.2003.08.011.

Chambers, L. 2016. Food texture and the satiety Cascade. Nutrition Bulletin 41 (3):277-82. doi: 10.1111/nbu.12221.

Chang, S. K., C. Alasalvar, and F. Shahidi. 2016. Review of dried fruits: Phytochemicals, antioxidant efficacies, and health benefits. Journal of Functional Foods 21:113-32. doi: 10.1016/j.jff.2015.11.034.

Chaovanalikit, A., and R. E. Wrolstad. 2004. Total anthocyanins and total phenolics of fresh and processed cherries and their antioxidant properties. Journal of Food Science 69 (1):FCT67-C72. doi: 10.1111/ j.1365-2621.2004.tb17858.x.

Chen, Y. G., L. J. Yu, and H. P. V. Rupasinghe. 2013. Effect of thermal and non-thermal pasteurisation on the microbial inactivation and phenolic degradation in fruit juice: a mini-review. Journal of the Science of Food and Agriculture 93 (5):981-6. doi: 10.1002/jsfa.5989.

Choi, M. H., G. H. Kim, and H. S. Lee. 2002. Effects of ascorbic acid retention on juice color and pigment stability in blood orange (Citrus sinensis) juice during refrigerated storage. Food Research International 35 (8):753-9. doi: Pii s00963-9969(02)0071-6 doi: 10 1016/S0963-9969(02)00071-6.

Cilla, A., A. Alegria, B. de Ancos, C. Sanchez-Moreno, M. P. Cano, L. Plaza, G. Clemente, M. J. Lagarda, and R. Barbera. 2012 Bioaccessibility of tocopherols, carotenoids, and ascorbic acid from milk- and soy-based fruit beverages: Influence of food matrix and processing. Journal of Agricultural and Food Chemistry 60 (29): 7282-90. doi: 10.1021/jf301165r.

Cilla, A., M. J. Lagarda, A. Alegría, B. de Ancos, M. P. Cano, C. Sánchez-Moreno, L. Plaza, and R. Barberá. 2011. Effect of processing and food matrix on calcium and phosphorous bioavailability from milk-based fruit beverages in Caco-2 cells. Food Research International 44 (9):3030-8. doi: 10.1016/j.foodres.2011.07.018.

Cilla, A., S. Perales, M. J. Lagarda, R. Barberá, G. Clemente, and R. Farré. 2011. Influence of storage and in vitro gastrointestinal digestion on total antioxidant capacity of fruit beverages. Journal of Food Composition and Analysis 24 (1):87-94. doi: 10.1016/j.jfca.2010.03.029.

Colin-Henrion, M., E. Mehinagic, C. Renard, P. Richomme, and F. Jourjon. 2009. From apple to applesauce: Processing effects on dietary fibres and cell wall polysaccharides. Food Chemistry 117 (2) 254-60. doi: 10.1016/j.foodchem.2009.03.109.

Cortés, C., M. J. Esteve, and A. Frígola. 2008. Effect of refrigerated storage on ascorbic acid content of orange juice treated by pulsed electric fields and thermal pasteurization. European Food Research and Technology 227 (2):629-35. doi: 10.1007/s00217-007-0766-x.

Cortes, C., F. Torregrosa, M. J. Esteve, and A. Frigola. 2006. Carotenoid profile modification during refrigerated storage in untreated and pasteurized orange juice and orange juice treated with high-intensity pulsed electric fields. Journal of Agricultural and Food Chemistry 54 (17):6247-54. doi: 10.1021/jf060995q.

Cravotto, G., and A. Binello. 2016. Chapter 1 - Low-frequency, highpower ultrasonic assisted food component extraction. In Innovative food processing techniques, ed. K. Knoerzer, P. Juliano, and G. Smithers. Cambridge: Woodhead Publishing Limited.

Dalmau, M. E., G. M. Bornhorst, V. Eim, C. Rosselló, and S. Simal. 2017. Effects of freezing, freeze drying and convective drying on in vitro gastric digestion of apples. Food Chemistry 215:7-16. doi: 10.1016/j.foodchem.2016.07.134

Darmon, N., F. Vieux, M. Maillot, J.-L. Volatier, and A. Martin. 2009. Nutrient profiles discriminate between foods according to their contribution to nutritionally adequate diets: a validation study using 
linear programming and the SAIN, LIM system. The American Journal of Clinical Nutrition 89 (4):1227-36. doi: 10.3945/ajcn.2008. 26465.

De Ancos, B., A. Cilla, R. Barberá, C. Sánchez-Moreno, and M. P. Cano. 2017. Influence of orange cultivar and mandarin postharvest storage on polyphenols, ascorbic acid and antioxidant activity during gastrointestinal digestion. Food Chemistry 225:114-24. doi: 10.1016/j. foodchem.2016.12.098.

Del Bo', C., P. Riso, A. Brambilla, C. Gardana, A. Rizzolo, P. Simonetti, ... M. Porrini. 2012. Blanching improves anthocyanin absorption from highbush blueberry (Vaccinium corymbosum L.) purée in healthy human volunteers: A pilot study. Journal of Agricultural and Food Chemistry 60 (36):9298-304. doi: 10.1021/ jf3021333.

Dewanto, V., X. Wu, and R. H. Liu. 2002. Processed sweet corn has higher antioxidant activity. Journal of Agricultural and Food Chemistry 50 (17):4959-64. doi: 10.1021/jf0255937.

Dewanto, V., X. Z. Wu, K. K. Adom, and R. H. Liu. 2002. Thermal processing enhances the nutritional value of tomatoes by increasing total antioxidant activity. Journal of Agricultural and Food Chemistry 50 (10):3010-4. doi: 10.1021/jf0115589.

Eichholz, I., S. Huyskens-Keil, A. Keller, D. Ulrich, L. W. Kroh, and S. Rohn. 2011. UV-B-induced changes of volatile metabolites and phenolic compounds in blueberries (Vaccinium corymbosum L.). Food Chemistry 126 (1):60-4. doi: 10.1016/j.foodchem.2010.10.071.

Elez-Martinez, P., and O. Martin-Belloso. 2007. Effects of high intensity pulsed electric field processing conditions on vitamin $\mathrm{C}$ and antioxidant capacity of orange juice and gazpacho, a cold vegetable soup. Food Chemistry 102 (1):201-9. doi: 10.1016/j.foodchem.2006.04.048.

Elizondo-Montemayor, L., C. Hernandez-Brenes, P. A. Ramos-Parra, D. Moreno-Sachez, B. Nieblas, A. M. Rosas-Perez, and A. C. Lamadrid-Zertuche. 2015. High hydrostatic pressure processing reduces the glycemic index of fresh mango puree in healthy subjects. Food \& Function 6 (4):1352-60. doi: 10.1039/C4FO01005A.

Fardet, A. 2015. A shift toward a new holistic paradigm will help to preserve and better process grain product food structure for improving their health effects. Food \& Function 6 (2):363-82. doi: 10.1039/ C4FO00477A.

Fardet, A. 2016. Minimally processed foods are more satiating and less hyperglycemic than ultra-processed foods: a preliminary study with 98 ready-to-eat foods. Food \& Function 7 (5):2338-46. doi: 10.1039/ C6FO00107F.

Fardet, A. 2017. L'effet matrice des aliments, un nouveau concept. Pratiques en Nutrition 13 (52):37-40. doi: 10.1016/j.pranut.2017.09.009.

Fardet, A., C. Méjean, H. Labouré, V. A. Andreeva, and G. Féron. 2017. The degree of processing of foods which are most widely consumed by the French elderly population is associated with satiety and glycemic potentials and nutrient profiles. Food \& Function 8 (2):651-8. doi: 10.1039/C6FO01495J.

Fardet, A., S. Lakhssassi, and A. Briffaz. 2018. Beyond nutritional-based food indices: a data mining approach to search for a quantitative holistic index reflecting the degree of food processing and including physicochemical properties. Food \& Function 9 (1):561-72. doi: 10. 1039/C7FO01423F.

Fardet, A., C. Richonnet, and A. Mazur. 2019. Association between fruit or processed fruit product consumption, chronic diseases and their risk factors: a systematic review of Meta-analyses. Nutrition Reviews 77 (6):376-87. doi: NUTR-REV-175-LA-08-2018.R1 doi: 10. 1093/nutrit/nuz004.

Fardet, A., and E. Rock. 2018. Reductionist nutrition research has meaning only within the framework of holistic thinking. Advances in Nutrition 9 (6):655-70. doi: 10.1093/advances/nmy044.

Fardet, A., I. Souchon, and D. Dupont. 2013. Structure des aliments et effets nutritionnels: Quae.

Fernandez-Garcia, E., F. Rincon, and A. Perez-Galvez. 2008. Developing an emulsifier system to improve the bioaccessibility of carotenoids. Journal of Agricultural and Food Chemistry 56 (21): 10384-90. doi: 10.1021/jf801910y.
Flood-Obbagy, J. E., and B. J. Rolls. 2009. The effect of fruit in differ- 2652 ent forms on energy intake and satiety at a meal. Appetite 52 (2): 2653 416-22. doi: 10.1016/j.appet.2008.12.001.

Foster-Powell, K., S. H. Holt, and J. C. Brand-Miller. 2002 2654 International table of glycemic index and glycemic load values: 2655 2002. The American Journal of Clinical Nutrition 76 (1):5-56. doi: 2656 10.1093/ajen/76.1.5.

Francis, F. J., and P. C. Markakis. 1989. Food colorants: Anthocyanins. 2658 Critical Reviews in Food Science and Nutrition 28 (4):273-314. doi: 2659 10.1080/10408398909527503.

Gazzani, G., A. Papetti, G. Massolini, and M. Daglia. 1998. Anti- and 2660 prooxidant activity of water soluble components of some common 2661 diet vegetables and the effect of thermal treatment. Journal of 2662 Agricultural and Food Chemistry 46 (10):4118-22. doi: 10.1021/ 2663 jf980300o.

Ha, M. A. J. I. Mann, L. D. Melton, and N. J. Lewisbarned 1992 2664 Relationship between the glycemic index and sugar content of fruits. 2665 Diabetes Nutrition \& Metabolism 5 (3):199-203.

Ha, V., A. I. Cozma, V. L. W. Choo, S. B. Mejia, R. J. de Souza, and 2667 J. L. Sievenpiper. 2015. Do fructose-containing sugars lead to 2668 adverse health consequences? results of recent systematic reviews 2669 and meta-analyses. Advances in Nutrition 6 (4):504S-11S. doi: 10. 2670 3945/an.114.007468.

Haber, G. B., K. W. Heaton, D. Murphy, and L. F. Burroughs. 1977. 2671 Depletion and disruption of dietary fibre. Effects on satiety, plasma- 2672 glucose, and serum-insulin. The Lancet 2 (8040):679-82. doi: 10. 2673 1016/S0140-6736(77)90494-9.

Hager, A., L. R. Howard, R. L. Prior, and C. Brownmiller. 2008. 2675 Processing and storage effects on monomeric anthocyanins, percent 2675 polymeric color, and antioxidant capacity of processed black rasp- 2676 berry products. Journal of Food Science 73 (6):H134-H40. doi: 10. 2677 1111/j.1750-3841.2008.00855.x.

Hager, T. J., L. R. Howard, and R. L. Prior. 2008. Processing and stor- 2679 age effects on monomeric anthocyanins, percent polymeric color, 2680 and antioxidant capacity of processed blackberry products. Journal 2681 of Agricultural and Food Chemistry 56 (3):689-95. doi: 10.1021/ 2681 jf071994g.

He, Z. Y., Y. D. Tao, M. M. Zeng, S. Zhang, G. J. Tao, F. Qin, and J. 2683 Chen. 2016. High pressure homogenization processing, thermal 2684 treatment and milk matrix affect in vitro bioaccessibility of phe- 2685 nolics in apple, grape and orange juice to different extents. Food 2686 Chemistry 200:107-16. doi: 10.1016/j.foodchem.2016.01.045.

Hendrickx, M., L. Ludikhuyze, I. Van den Broeck, and C. Weemaes. 2687
1998. Effects of high pressure on enzymes related to food quality. 2688 Trends in Food Science \& Technology 9 (5):197-203. doi: 10.1016/ 2689 S0924-2244(98)00039-9.

2690

Hochuli, M., I. Aeberli, P. Gerber, H. Troxler, L. Sze, S. Murer, G. Spinas, and K. Berneis. 2012. Moderate amounts of sugar sweetened beverages impair hepatic insulin sensitivity and lipid metabolism, 2692 including Beta-Oxidation of fatty acids, in healthy young Men-A 2693 randomized controlled trial. Diabetes 61 (Supplement 1):2797.

Holt, S. H., J. C. Miller, P. Petocz, and E. Farmakalidis. 1995. A satiety 2695 index of common foods. European Journal of Clinical Nutrition 492696 (9):675-90

Houchins, J. A., S. Y. Tan, W. W. Campbell, and R. D. Mattes. 2013. 2697 Effects of fruit and vegetable, consumed in solid vs beverage forms, 2698
on acute and chronic appetitive responses in lean and obese adults. 2699 International Journal of Obesity 37 (8):1109-15. doi: 10.1038/ijo. 2700 2012.183.

2701

Huyskens-Keil, S., I. Eichholz, L. W. Kroh, and S. Rohn. 2007. UV-B 2702 induced changes of phenol composition and antioxidant activity in 2702
black currant fruit (Ribes nigrum L. ). Journal of Applied Botany 2703 and Food Quality-Angewandte Botanik 81 (2):140-4.

Imamura, F., L. O'Connor, Z. Ye, J. Mursu, Y. Hayashino, S. N. 2705 Bhupathiraju, and N. G. Forouhi. 2016. Consumption of sugar 2706 sweetened beverages, artificially sweetened beverages, and fruit juice 2706 and incidence of type 2 diabetes: systematic review, Meta-analysis, 2707 and estimation of population attributable fraction. British Journal of 2708 Sports Medicine 50 (8):496-504. doi: 10.1136/bjsports-2016- 2709 h3576rep. 
Ishiwata, K., T. Yamaguchi, H. Takamura, and T. Matoba. 2004. DPPH radical-scavenging activity and polyphenol content in dried fruits. Food Science and Technology Research 10 (2):152-6. doi: 10.3136/ fstr.10.152.

Jackman, R. L., R. Y. Yada, and M. A. Tung. 1987. A review - separation and chemical-properties of anthocyanins used for their qualitative and quantitative-analysis. Journal of Food Biochemistry 11 (4): 279-308. doi: 10.1111/j.1745-4514.1987.tb00128.x.

Jang, C., S. Hui, W. Lu, A. J. Cowan, R. J. Morscher, G. Lee, W. Liu, G. J. Tesz, M. J. Birnbaum, and J. D. Rabinowitz. 2018. The small intestine converts dietary fructose into glucose and organic acids. Cell Metabolism 27 (2):351-61. doi: 10.1016/j.cmet.2017.12.016.

Jeong, S. M., S. Y. Kim, D. R. Kim, S. C. Jo, K. C. Nam, D. U. Ahn, and S. C. Lee. 2004. Effect of heat treatment on the antioxidant activity of extracts from citrus peels. Journal of Agricultural and Food Chemistry 52 (11):3389-93. doi: 10.1021/jf049899k.

Jimenez, G., G. Gomez, A. M. Perez, and A. Blanco-Metzler. 2012. Estimation of glycaemic index of peach palm (Bactris gasipaes) cooked fruits and chips, and pitahaya (Hylocereus spp.) pulp. Archivos Latinoamericanos de Nutricion 62 (3):242-8.

Kalt, W., J. E. McDonald, and H. Donner. 2000. Anthocyanins, phenolics, and antioxidant capacity of processed lowbush blueberry products. Journal of Food Science 65 (3):390-3. doi: 10.1111/j.13652621.2000.tb16013.x.

Kamiloglu, S., and E. Capanoglu. 2013. Investigating the in vitro bioaccessibility of polyphenols in fresh and sun-dried figs (Ficus carica L.). International Journal of Food Science \& Technology 48 (12): 2621-9. doi: 10.1111/ijfs.12258.

Kammerer, D., R. Carle, and A. Schieber. 2004. Quantification of anthocyanins in black carrot extracts (Daucus carota ssp sativus var. atrorubens Alef.) and evaluation of their color properties. European Food Research and Technology 219 (5):479-86. doi: 10.1007/s00217004-0976-4.

Katsilambros, N., P. Philippides, J. Boletis, K. Mavroudis, D. Frangaki, M. Marangos, and G. K. Daikos. 1985. Postprandial hyperglycemia after ingestion of peeled and non-peeled fruits in type 2 diabetics. Journal of Endocrinological Investigation 8 (3):189-91. doi: 10.1007/ BF03348474.

Krifi, B., and M. Metche. 2000. Degradation of anthocyanins from blood orange juices. International Journal of Food Science and Technology 35 (3):275-83. doi: 10.1046/j.1365-2621.2000.00330.x.

Kurotobi, T., K. Fukuhara, H. Inage, and S. Kimura. 2010. Glycemic index and postprandial blood glucose response to japanese strawberry jam in normal adults. Journal of Nutritional Science and Vitaminology 56 (3):198-202. doi: 10.3177/jnsv.56.198.

Lee, J., R. W. Durst, and R. E. Wrolstad. 2002. Impact of juice processing on blueberry anthocyanins and polyphenolics: Comparison of two pretreatments. Journal of Food Science 67 (5):1660-7. doi: 10. 1111/j.1365-2621.2002.tb08701.x.

Légifrance. 2001. Directive 2001/112/CE du Conseil relative aux jus de fruits et à certains produits similaires destinés à l'alimentation humaine. Accessed May 29, 2019. https://www.legifrance.gouv.fr/ affichTexte.do? cidTexte=JORFTEXT000000331003\&categorieLien=id. Lettieri-Barbato, D., F. Tomei, A. Sancini, G. Morabito, and M. Serafini. 2013. Effect of plant foods and beverages on plasma nonenzymatic antioxidant capacity in human subjects: A meta-analysis. British Journal of Nutrition 109 (9):1544-56. doi: 10.1017/ S0007114513000263.

Li, F., X. Bo-Tao, X. Xiang-Rong, G. Ren-You, Z. Yuan, X. En-Qin, and L. Hua-Bin. 2011. Antioxidant capacities and total phenolic contents of 62 fruits. Food Chemistry 129 (2):345-50. doi: 10.1016/j. foodchem.2011.04.079.

Markaris, P., G. E. Livingston, and C. R. Fellers. 1957. Quantitative aspects of strawberry pigment degradation. Journal of Food Science 22 (2):117-30. doi: 10.1111/j.1365-2621.1957.tb16991.x.

McKeown, N. M., H. S. Dashti, J. Ma, D. E. Haslam, J. C. Kiefte-de Jong, C. E. Smith, T. Tanaka, M. Graff, R. N. Lemaitre, D. Rybin, et al. 2018. Sugar-sweetened beverage intake associations with fasting glucose and insulin concentrations are not modified by selected genetic variants in a ChREBP-FGF21 pathway: A meta-analysis. Diabetologia 61 (2):317-30. doi: 10.1007/s00125-017-4475-0.

Miller, H. E., F. Rigelhof, L. Marquart, A. Prakash, and M. Kanter. 2000. Antioxidant content of whole grain breakfast cereals, fruits and vegetables. Journal of the American College of Nutrition 19 (sup3):312S-9S. doi: 10.1080/07315724.2000.10718966.

Min, S., G. A. Evrendilek, and H. Q. Zhang. 2007. Pulsed electric fields: Processing system, microbial and enzyme inhibition, and shelf life extension of foods. IEEE Transactions on Plasma Science 35 (1) 59-73. doi: 10.1109/TPS.2006.889290.

Min, S., Z. T. Jin, S. K. Min, H. Yeom, and Q. H. Zhang. 2003 Commercial-scale pulsed electric field processing of orange juice. Journal of Food Science 68 (4):1265-71. doi: 10.1111/j.1365-2621.2003.tb09637.x.

Monteiro, C., G. Cannon, R. Levy, J. C. Moubarac, P. Jaime, A. Martins, et al. 2016. The star shines bright. World Nutrition 7 (1-3):28-38.

Monteiro, C. A., G. Cannon, J.-C. Moubarac, R. B. Levy, M. L. C Louzada, and P. C. Jaime. 2018. The UN decade of nutrition, the NOVA food classification and the trouble with ultra-processing. Public Health Nutrition 21 (1):5-17. doi: 10.1017/S1368980017000234.

Moorhead, S. A., M. B. E. Livingstone, A. Dunne, and R. W. Welch 2008. The level of carbonation of a sugar-sweetened beverage preload affects satiety and short-term energy and food intakes. British Journal of Nutrition 99 (6):1362-9. doi: 10.1017/S0007114507871662.

Moshonas, M. G., and P. E. Shaw. 1997. Flavor and chemical comparison of pasteurized and fresh Valencia orange juices. Journal of Food Quality 20 (1):31-40. doi: 10.1111/j.1745-4557.1997.tb00449.x.

Moubarac, J.-C., D. C. Parra, G. Cannon, and C. A. Monteiro. 2014 Food classification systems based on food processing: Significance and implications for policies and actions: a systematic literature review and assessment. Current Obesity Reports 3 (2):256-72. doi 10.1007/s13679-014-0092-0.

Mourao, D. M., J. Bressan, W. W. Campbell, and R. D. Mattes. 2007. Effects of food form on appetite and energy intake in lean and obese young adults. International Journal of Obesity 31 (11):1688-95. doi: 10.1038/sj.ijo.0803667.

Nagy, S., R. L. Rouseff, and H. S. Lee. 1989. Thermally degraded flavors in citrus juice products. In Thermal generation of aromas, ed. T. H Parliament, R. J. McGorin, and C.-T. Ho, Vol. 409, 331-45. Washington, DC: American Chemical Society.

Nayak, B., R. H. Liu, and J. M. Tang. 2015. Effect of processing on phenolic antioxidants of fruits, vegetables, and Grains-A review. Critical Reviews in Food Science and Nutrition 55 (7):887-918. doi: 10.1080/10408398.2011.654142.

Ngo, T., R. E. Wrolstad, and Y. Zhao. 2007. Color quality of Oregon strawberries - Impact of genotype, composition, and processing Journal of Food Science 72 (1):C025-C32. doi: 10.1111/j.1750-3841. 200600200.x.

Noci, F., J. Riener, M. Walkling-Ribeiro, D. A. Cronin, D. J. Morgan, and J. G. Lyng. 2008. Ultraviolet irradiation and pulsed electric fields (PEF) in a hurdle strategy for the preservation of fresh apple juice. Journal of Food Engineering 85 (1):141-6. doi: 10.1016/j.jfoodeng.2007.07.011.

Odriozola-Serrano, I., I. Aguiló-Aguayo, R. Soliva-Fortuny, V. GimenoAñó, and O. Martín-Belloso. 2007. Lycopene, vitamin C, and antioxidant capacity of tomato juice as affected by High-Intensity pulsed electric fields critical parameters. Journal of Agricultural and Food Chemistry 55 (22):9036-42. doi: 10.1021/jf0709101.

Odriozola-Serrano, I., R. Soliva-Fortuny, V. Gimeno-Añó, and O. Martín-Belloso, 2008. Kinetic study of anthocyanins, vitamin C, and antioxidant capacity in strawberry juices treated by high-intensity pulsed electric fields. Journal of Agricultural and Food Chemistry 56 (18):8387-93. doi: 10.1021/jf801537f.

Odriozola-Serrano, I., R. Soliva-Fortuny, and O. Martín-Belloso. 2008a. Changes of health-related compounds throughout cold storage of tomato juice stabilized by thermal or high intensity pulsed electric field treatments. Innovative Food Science \& Emerging Technologies 9 (3):272-9. doi: 10.1016/j.ifset.2007.07.009.

Odriozola-Serrano, I., R. Soliva-Fortuny, and O. Martín-Belloso. 2008b. Phenolic acids, flavonoids, vitamin $\mathrm{C}$ and antioxidant capacity of strawberry juices processed by high-intensity pulsed electric fields or 
heat treatments. European Food Research and Technology 228 (2) 239. doi: 10.1007/s00217-008-0928-5.

Ornelas-Paz, J. D. J., M. L. Failla, E. M. Yahia, and A. Gardea-Bejar. 2008. Impact of the stage of ripening and dietary fat on in vitro bioaccessibility of beta-carotene in 'ataulfo' mango. Journal of Agricultural and Food Chemistry 56 (4):1511-6. doi: 10.1021/jf07275lr.

Oszmianski, J., M. Wolniak, A. Wojdylo, and I. Wawer. 2008. Influence of apple puree preparation and storage on polyphenol contents and antioxidant activity. Food Chemistry 107 (4):1473-84 doi: 10.1016/j.foodchem.2007.10.003.

Ouyang, X., P. Cirillo, Y. Sautin, S. McCall, J. L. Bruchette, A. M. Diehl, R. J. Johnson, and M. F. Abdelmalek. 2008. Fructose consumption as a risk factor for non-alcoholic fatty liver disease. Journal of Hepatology 48 (6):993-9. doi: 10.1016/j.jhep.2008.02.011.

Parada, J., and J. M. Aguilera. 2007. Food microstructure affects the bioavailability of several nutrients. Journal of Food Science 72 (2): R21-R32. doi: 10.1111/j.1750-3841.2007.00274.x.

Parker, T. L., X. H. Wang, J. Pazmino, and N. J. Engeseth. 2007. Antioxidant capacity and phenolic content of grapes, sun-dried raisins, and golden raisins and their effect on ex vivo serum antioxidant capacity. Journal of Agricultural and Food Chemistry 55 (21): 8472-7. doi: 10.1021/jf071468p.

Patras, A., N. P. Brunton, S. Da Pieve, and F. Butler. 2009. Impact of high pressure processing on total antioxidant activity, phenolic, ascorbic acid, anthocyanin content and colour of strawberry and blackberry purées. Innovative Food Science \& Emerging Technologies 10 (3):308-13. doi: 10.1016/j.ifset.2008.12.004.

Patterson, M. F. 2014. Food technologies: High pressure processing. In Encyclopedia of food safety (vol. 3: Foods, materials, technologies and risks, ed. Y. Motarjemi, pp. 196-201. Waltham: Academic Press.

Pellegrini, N., M. Serafini, S. Salvatore, D. Del Rio, M. Bianchi, and F. Brighenti. 2006. Total antioxidant capacity of spices, dried fruits, nuts, pulses, cereals and sweets consumed in Italy assessed by three different in vitro assays. Molecular Nutrition \& Food Research 50 (11):1030-8. doi: 10.1002/mnfr.200600067.

Pérez, A. G., C. Sanz, J. J. Ríos, R. Olías, and J. M. Olías. 1999. Effects of ozone treatment on postharvest strawberry quality. Journal of Agricultural and Food Chemistry 47 (4):1652-6. doi: 10.1021/jf9808291

Piquet, F. 2012. Guide de l'équilibre acide-base: Thierry Souccar Editions. France: Vergèze.

Plaza, L., C. Sanchez-Moreno, B. De Ancos, P. Elez-Martinez, O. MartinBelloso, and M. P. Cano. 2011. Carotenoid and flavanone content during refrigerated storage of orange juice processed by high-pressure, pulsed electric fields and low pasteurization. Lwt - Food Science and Technology 44 (4):834-9. doi: 10.1016/j.lwt.2010.12.013.

Proteggente, A. R., A. S. Pannala, G. Paganga, L. Van Buren, E. Wagner, S. Wiseman, F. Van De Put, C. Dacombe, and C. A. Rice-Evans. 2002. The antioxidant activity of regularly consumed fruit and vegetables reflects their phenolic and vitamin C composition. Free Radical Research 36 (2):217-33. doi: 10.1080/10715760290006484.

Puértolas, E., P. Hernández-Orte, G. Sladaña, I. Álvarez, and J. Raso. 2010. Improvement of winemaking process using pulsed electric fields at pilot-plant scale. Evolution of chromatic parameters and phenolic content of Cabernet Sauvignon red wines. Food Research International 43 (3):761-6. doi: 10.1016/j.foodres.2009.11.005.

Qiu, X., S. Sharma, L. Tuhela, M. Jia, and Q. H. Zhang. 1998. An integrated PEF pilot plant for continuous nonthermal pasteurization of fresh orange juice. Transactions of the Asae 41 (4):1069-74.

Rababah, T. M., K. I. Ereifej, and L. Howard. 2005. Effect of ascorbic acid and dehydration on concentrations of total phenolics, antioxidant capacity, anthocyanins, and color in fruits. Journal of Agricultural and Food Chemistry 53 (11):4444-7. doi: 10.1021/jf0502810.

Rankin, J. W., M. C. Andreae, C.-Y. Oliver Chen, and S. F. O'Keefe. 2008. Effect of raisin consumption on oxidative stress and inflammation in obesity. Diabetes, Obesity and Metabolism 10 (11): 1086-96. doi: 10.1111/j.1463-1326.2008.00867.x.

Remer, T., and F. Manz. 1995. Potential renal acid load of foods and its influence on urine $\mathrm{pH}$. Journal of the American Dietetic Association 95 (7):791-7. doi: 10.1016/S0002-8223(95)00219-7.
Rodrigo, M. J., A. Cilla, R. Barbera, and L. Zacarias. 2015. Carotenoid 2888 bioaccessibility in pulp and fresh juice from carotenoid-rich sweet 2889 oranges and mandarins. Food \& Function 6 (6):1950-9. doi: 10. 2890 1039/C5FO00258C

Rodriguez-Roque, M. J., B. de Ancos, C. Sanchez-Moreno, M. P. Cano, 2891 P. Elez-Martinez, and O. Martin-Belloso. 2015. Impact of food 2892 matrix and processing on the in vitro bioaccessibility of vitamin C, 2893 phenolic compounds, and hydrophilic antioxidant activity from fruit 2894 juice-based beverages. Journal of Functional Foods 14:33-43. doi: 10. 2895 1016/j.jff.2015.01.020

Rodriguez-Roque, M. J., B. de Ancos, R. Sanchez-Vega, C. Sanchez- 2896 Moreno, M. P. Cano, P. Elez-Martinez, and O. Martin-Belloso. 2016. 2897 Food matrix and processing influence on carotenoid bioaccessibility 2898 and lipophilic antioxidant activity of fruit juice-based beverages. 2899 Food \& Function 7 (1):380-9. doi: 10.1039/C5FO01060H.

Rodriguez-Saona, L. E., M. M. Giusti, and R. E. Wrolstad 1999. Color 2900 and pigment stability of red radish and Red-Fleshed potato antho- 2901 cyanins in juice model systems. Journal of Food Science 64 (3): 2902 451-6. doi: 10.1111/j.1365-2621.1999.tb15061.x.

Rossi, M., E. Giussani, R. Morelli, R. Lo Scalzo, R. C. Nani, and D. 2904 Torreggiani. 2003. Effect of fruit blanching on phenolics and radical 2905 scavenging activity of highbush blueberry juice. Food Research 2906 International 36 (9-10):999-1005. doi: 10.1016/j.foodres.2003.07.002.

Ruanpeng, D., C. Thongprayoon, W. Cheungpasitporn, and T. 2907 Harindhanavudhi. 2017. Sugar and artificially sweetened beverages 2908 linked to obesity: a systematic review and Meta-analysis. Qjm: An 2909 International Journal of Medicine 110 (8):513-20. doi: 10.1093/2910 qjimed/hcx068.

Rufino, M. S. M., R. E. Alves, E. S. de Brito, J. Pérez-Jiménez, F. Saura- 2911 Calixto, and J. Mancini-Filho. 2010. Bioactive compounds and antioxi- 2912 dant capacities of 18 non-traditional tropical fruits from Brazil. Food 2913 Chemistry 121 (4):996-1002. doi: 10.1016/j.foodchem.2010.01.037. 2914

Ryan, L., and S. L. Prescott. 2010. Stability of the antioxidant capacity 2915 of twenty-five commercially available fruit juices subjected to an 2916 in vitro digestion. International Journal of Food Science \& 2916 Technology 45 (6):1191-7. doi: 10.1111/j.1365-2621.2010.02254.x.

Santangelo, C., R. Vari, B. Scazzocchio, R. Di Benedetto, C. Filesi, and 2918 R. Masella. 2007. Polyphenols, intracellular signaling and inflamma- 2919 tion. Annali dell'Istituto Superiore di Sanità 43 (4):394-405.

Santos, P. H. S., and M. A. Silva. 2008. Retention of vitamin C in dry- 2921 ing processes of fruits and vegetables - A review. Drying Technology 2922 26 (12):1421-37. Pii 905553186. doi: 10.1080/07373930802458911.

Scalbert, A., C. Morand, C. Manach, and C. Remesy. 2002. Absorption 2923
and metabolism of polyphenols in the gut and impact on health. 2924 Biomedicine \& Pharmacotherapy 56 (6):276-82. doi: 10.1016/S0753- 2925 3322(02)00205-6.

Schulz, M., F. C. Biluca, L. V. Gonzaga, G. d. S. C. Borges, L. Vitali, G. A. Micke, J. S. de Gois, T. S. de Almeida, D. L. G. Borges, 2927 P. R. M. Miller, et al. 2017. Bioaccessibility of bioactive compounds 2928 and antioxidant potential of jucara fruits (Euterpe edulis Martius) 2929 subjected to in vitro gastrointestinal digestion. Food Chemistry 228: 2930 447-54. doi: 10.1016/j.foodchem.2017.02.038.

SELF Nutrition Data. 2014. Fullness Factor ${ }^{\text {TM }}$. Accessed May 2019, 2931 https://nutritiondata.self.com/topics/fullness-factor.

Serafini, M., A. Ghiselli, and A. Ferro-Luzzi. 1996. In vivo antioxidant 2933 effect of green and black tea in man. European Journal of Clinical 2934 Nutrition 50 (1):28-32.

Serafini, M., and I. Peluso. 2017. Functional foods for health: the inter- 2936 related antioxidant and anti-inflammatory role of fruits, vegetables, 2937 herbs, spices and cocoa in humans. Current Pharmaceutical Design 22 (44):6701-15. doi: 10.2174/1381612823666161123094235.

Serafini, M., M. F. Testa, D. Villaño, M. Pecorari, K. van Wieren, E. 2939 Azzini, A. Brambilla, and G. Maiani. 2009. Antioxidant activity of 2940 blueberry fruit is impaired by association with milk. Free Radical 2941 Biology and Medicine 46 (6):769-74. doi: 10.1016/j.freeradbiomed. 2942 2008.11.023

Sharma, H. P., Patel, and H. Sugandha. 2017. Enzymatic added extrac- 2943 tion and clarification of fruit juices-A review. Critical Reviews in 2944 Food Science and Nutrition 57 (6):1215-27. doi: 10.1080/10408398. 2945 2014.977434 
Skrede, G., R. E. Wrolstad, and R. W. Durst. 2000. Changes in anthocyanins and polyphenolics during juice processing of highbush blueberries (Vaccinium corymbosum L.). Journal of Food Science 65 (2): 357-64. doi: 10.1111/j.1365-2621.2000.tb16007.x.

Spanos, G. A., and R. E. Wrolstad. 1992. Phenolics of apple, pear, and white grape juices and their changes with processing and storage - a review. Journal of Agricultural and Food Chemistry 40 (9):1478-87. doi: $10.1021 /$ jf00021a002.

Spencer, C. M., Y. Cai, R. Martin, S. H. Gaffney, P. N. Goulding, D. Magnolato, T. H. Lilley, and E. Haslam. 1988. Polyphenol complexation-some thoughts and observations. Phytochemistry 27 (8): 2397-409. doi: 10.1016/0031-9422(88)87004-3.

Stinco, C. M., R. Fernandez-Vazquez, M. L. Escudero-Gilete, F. J. Heredia, A. J. Melendez-Martinez, and I. M. Vicario. 2012. Effect of orange juice's processing on the color, particle size, and bioaccessibility of carotenoids. Journal of Agricultural and Food Chemistry 60 (6):1447-55. doi: 10.1021/jf2043949.

Stinco, C. M., R. Fernandez-Vazquez, F. J. Heredia, A. J. MelendezMartinez, and I. M. Vicario. 2013. Bioaccessibility, antioxidant activity and colour of carotenoids in ultrafrozen orange juices: Influence of thawing conditions. Lwt - Food Science and Technology 53 (2): 458-63. doi: 10.1016/j.lwt.2013.04.003.

Sun, J., Y.-F. Chu, X. Wu, and R. H. Liu. 2002. Antioxidant and antiproliferative activities of common fruits. Journal of Agricultural and Food Chemistry 50 (25):7449-54. doi: 10.1021/jf0207530.

Takeda, T., M. Inomata, H. Matsuoka, M. Hikuma, and S. Furusaki. 2003. Release of anthocyanin from strawberry cultured cells with heating treatment. Biochemical Engineering Journal 15 (3):205-10. doi: 10.1016/S1369-703X(02)00213-9.

Tey, S. L., D. E. M. Lee, and C. J. Henry. 2017. Fruit form influences postprandial glycemic response in elderly and young adults. The Journal of Nutrition, Health \& Aging 21 (8):887-91. doi: 10.1007/ s12603-017-0880-9.

Threlfall, R., J. Morris, and J.-F. Meullenet. 2007. Product development and nutraceutical analysis to enhance the value of dried fruit. Journal of Food Quality 30 (4):552-66. doi: 10.1111/j.1745-4557. 2007.00142.x.

Tonin, F. S., L. M. Steimbach, A. Wiens, C. M. Perlin, and R. Pontarolo. 2015. Impact of natural juice consumption on plasma antioxidant status: A systematic review and meta-analysis. Molecules 20 (12):22146-56. doi: 10.3390/molecules201219834.

Toydemir, G., E. Capanoglu, S. Kamiloglu, D. Boyacioglu, R. C. H. de Vos, R. D. Hall, and J. Beekwilder. 2013. Changes in sour cherry (Prunus cerasus L.) antioxidants during nectar processing and in vitro gastrointestinal digestion. Journal of Functional Foods 5 (3): 1402-13. doi: 10.1016/j.jff.2013.05.008.

U.S. Department of Agriculture, Agricultural Research Service, Nutrient Data Laboratory. 2005. USDA National Nutrient Database for Standard Reference, Release 18, Fruits and fruit juices. Accessed August 1, 2011. http://www.nal.usda.gov/fnic/foodcomp/Data/SR18/ reports/sr18page.htm.

Valentová, K., D. Stejskal, P. Bednář, J. Vostálová, Č. Číhalík, R. VecEřová, D. Koukalová, M. Kolář, R. Reichenbach, L. Škňouřil, et al. 2007. Biosafety, antioxidant status, and metabolites in urine after consumption of dried cranberry juice in healthy women: A pilot double-blind placebo-controlled trial. Journal of Agricultural and Food Chemistry 55 (8):3217-24. doi: 10.1021/jf0636014.

Vatanasuchart, N., P. Butsuwan, and W. Narasri. 2015. Nutritional composition, in vitro starch digestibility and estimated glycemic index of three varieties of 'kluai Namwa' banana (Musa sapientum L.) and its products. Maejo International Journal of Science and Technology 9 (2):265-77.

Vinson, J. A., L. Zubik, P. Bose, N. Samman, and J. Proch. 2005. Dried fruits: Excellent in vitro and in vivo antioxidants. Journal of the American College of Nutrition 24 (1):44-50. doi: 10.1080/07315724. 2005.10719442.

Wang, H., G. H. Cao, and R. L. Prior. 1996. Total antioxidant capacity of fruits. Journal of Agricultural and Food Chemistry 44 (3):701-5. doi: $10.1021 /$ jf950579y.

Wang, M., M. Yu, L. Fang, and R. Y. Hu. 2015. Association between sugar-sweetened beverages and type 2 diabetes: a Meta-analysis. Journal of Diabetes Investigation 6 (3):360-6. doi: 10.1111/jdi.12309.

Wills, R. B. H., J. C. B. Miller, and K. M. Matawie. 1998. Relationship between glycaemic index and nutrient composition of fruit and vegetables. International Journal of Food Properties 1 (2):89-94. doi: 10. 1080/10942919809524569.

Wilson, T., S. L. Meyers, A. P. Singh, P. J. Limburg, and N. Vorsa 2008. Favorable glycemic response of type 2 diabetics to LowCalorie cranberry juice. Journal of Food Science 73 (9):H241-5. doi: 10.1111/j.1750-3841.2008.00964.x.

Wilson, T., A. P. Singh, N. Vorsa, C. D. Goettl, K. M. Kittleson, C. M. Roe, G. M. Kastello, and F. R. Ragsdale. 2008. Human glycemic response and phenolic content of unsweetened cranberry juice. Journal of Medicinal Food 11 (1):46-54. doi: 10.1089/jmf.2007.531.

Wrolstad, R. E., G. Skrede, P. E. R. Lea, and G. Enersen. 1990. Influence of sugar on anthocyanin pigment stability in frozen strawberries. Journal of Food Science 55 (4):1064-5. doi: 10.1111/j.13652621.1990.tb01598.x.

Wu, X., G. R. Beecher, J. M. Holden, D. B. Haytowitz, S. E. Gebhardt, and R. L. Prior. 2004. Lipophilic and hydrophilic antioxidant capacities of common foods in the United States. Journal of Agricultural and Food Chemistry 52 (12):4026-37. doi: 10.1021/jf049696w.

Xue, Z. H., J. M. Li, W. C. Yu, X. T. Lu, and X. H. Kou. 2016. Effects of nonthermal preservation technologies on antioxidant activity of fruits and vegetables: A review. Food Science and Technology International 22 (5):440-58. doi: 10.1177/1082013215606835.

Zhang, L., Z. Lu, Z. Yu, and X. Gao. 2005. Preservation of fresh-cut celery by treatment of ozonated water. Food Control 16 (3):279-83. doi: 10.1016/j.foodcont.2004.03.007.

Zhang, Y., X. Liao, Y. Ni, J. Wu, X. Hu, Z. Wang, and F. Chen. 2007. Kinetic analysis of the degradation and its color change of cyanidin3-glucoside exposed to pulsed electric field. European Food Research and Technology 224 (5):597-603. doi: 10.1007/s00217-006-0343-8.

Zulueta, A., F. J. Barba, M. J. Esteve, and A. Frígola. 2010. Effects on the carotenoid pattern and vitamin a of a pulsed electric fieldtreated orange juice-milk beverage and behavior during storage. European Food Research and Technology 231 (4):525-34. doi: 10. 1007/s00217-010-1304-9.
3006

3007

3008

3009

3010

3011

3012

3013

3014

3015

3016

3017

3018

3019

3020

3021

3022

3023

3024

3025

3026

3027

3028

3029

3030

3031

3032

3033

3034

3035

3036

3037

3038

3039

3040

3041

3042

3043

3044

3045

3046

3047

3048

3049

3050

3051

3052

3053

3054

3055

3056

3057

3058

3059

3060

3061

3062

3063

3064 